\title{
Approach to the Socio-Economic Activity of Countries with a Social Accounting Matrices Supported by Socio- Demographic Matrices: An Application to Portugal
}

\section{Pages Posted: 27 Nov 2014}

\section{Susana Santos}

ISEG (School of Economics and Management) of the University of Lisboa; UECE (Research Unit on Complexity and Economics) and DE (Department of Economics)

Date Written: November 25, 2014

\section{Suggested Citation:}

Santos, Susana, Approach to the Socio-Economic Activity of Countries with a Social Accounting Matrices Supported by Socio-Demographic Matrices: An Application to Portugal (November 25, 2014). Available at SSRN: https://ssrn.com/abstract $=2530735$ or http://dx.doi.org/10.2139/ssrn.2530735 


\title{
Approach to the socio-economic activity of countries with a Social Accounting Matrices supported by Socio-Demographic Matrices. An application to Portugal.
}

\author{
SUSANA SANTOS \\ ISEG (School of Economics and Management) of the University of Lisbon \\ UECE (Research Unit on Complexity and Economics) and DE (Department of Economics). \\ Rua Miguel Lupi, 20, 1249-078 Lisboa, Portugal; \\ Tel.: +351213925912 \\ E-mail:ssantos@iseg.ulisboa.pt
}

Keywords: Social Accounting Matrix; National Accounts; Socio-Demographic Matrices.

JEL classification: C82; E01; E16; E61; J11.

(November 2014)

Notes:

- The financial support from national funds provided by FCT (Fundação para a Ciência e a Tecnologia), Portugal, is gratefully acknowledge. This paper is part of the Strategic Project for 2014 (PEst-OE/EGE/UI0436/2014)

- This paper is based on the intervention at the Inaugural Conference of SEM, promoted by SEM (Society for Economic Measurement)), held in Chicago, USA, August, 18-20, 2014. 


\begin{abstract}
:
Social Accounting Matrices (SAMs) will be presented as tools that have specific features for studying the socio-economic activity of countries. Such features allow for the reading and interpretation of the reality under study, leading to the production of an empirical work that is not only capable of highlighting specific aspects of that activity, but also offers the chance to experiment with different interventions in regard to its functioning. In stating that the knowledge of the socio-economic activity of countries involves the use of national accounts, emphasis is placed on the desirability of working in a matrix format, which simultaneously includes activities (or industries), products, factors of production and institutions. This will be considered to be a way of capturing the relevant network of linkages and the corresponding multiplier effects in the subsequent modelling of the socio-economic activity of the countries studied.

A methodological framework based on the works of R. Stone, G. Pyatt and J. Round, will be adopted outlining the main features of the SAM-based approach, according to which the SAM can describe the activity of countries either empirically or theoretically, depending on whether it is presented in a numerical or an algebraic version, respectively.

Based on the latest version of the System of National Accounts (2008 SNA), a proposal for a numerical version of a SAM will be presented. Firstly, a basic structure will be presented and the need to ensure its consistency with the whole system will be emphasized. Such emphasis will then be reinforced through the analysis of possible disaggregations and extensions to that basic structure. The different forms of analysis made possible by the use of aggregates, indicators and balancing items that can be calculated from such a version and which lie outside the matrix format will also be discussed.
\end{abstract}

Because any socio-economic study made of a specific space, namely, a country, should involve the consideration of its population, Socio-Demographic Matrices (SDMs) will also be briefly presented and two examples of approaches based on SAMs and SDMs will be sketched out.

The exposition will be illustrated with an application to Portugal. 


\section{CONTENTS}

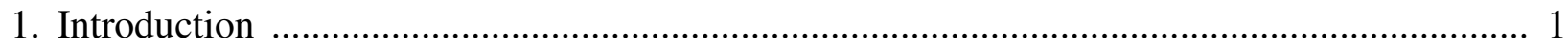

2. Looking for empirical evidence about the activity of countries.......................................... 2

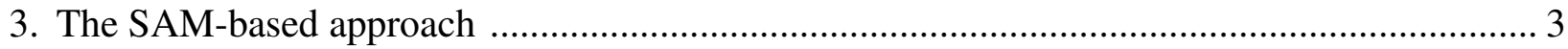

4. Constructing numerical versions of SAMs from the SNA ............................................... 5

4.1. The SAM's basic structure and its consistency with the whole system ......................... 6

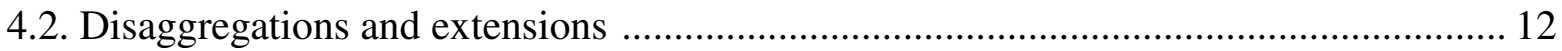

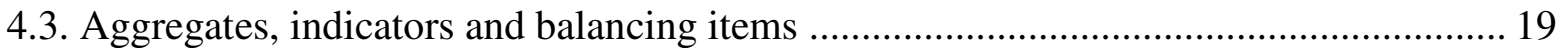

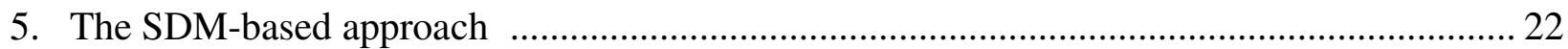

6. Examples of studies that can be addressed using a SAM, with the support of a SDM

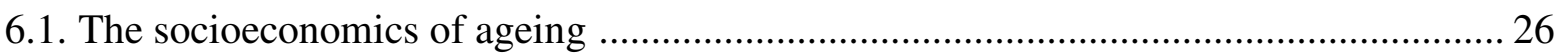

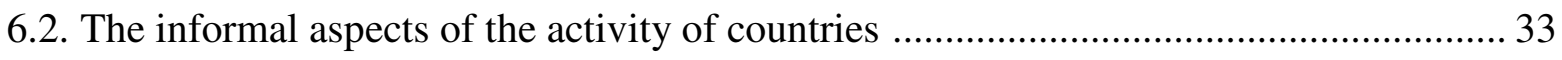

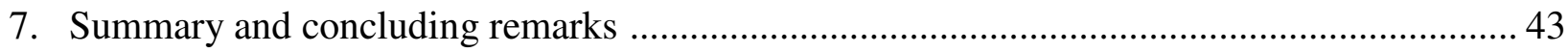

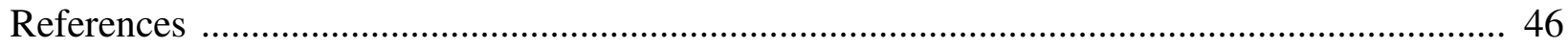




\section{List of Tables}

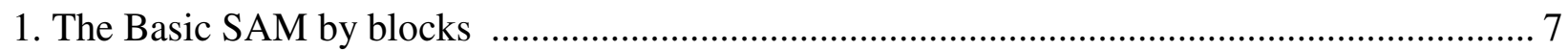

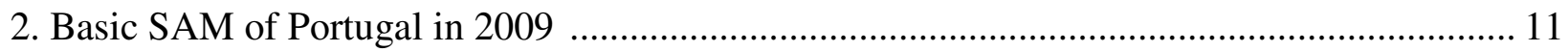

3. SAM of Portugal in 2009, with disaggregated factors of production and the (domestic)

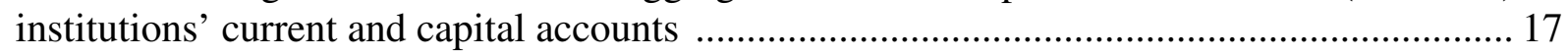

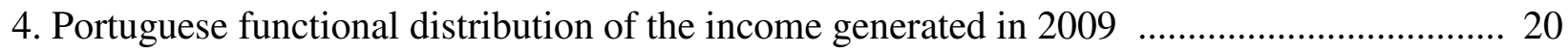

5. Portuguese institutional distribution of the income generated in 2009 ................................. 21

6. Portuguese distribution and use of disposable income among institutions in 2009 ............... 21

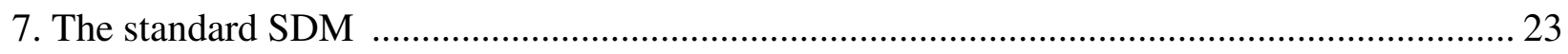

8. SDM of Portugal in 2009 - first level of disaggregation: by age group .............................. 24

9. SDM of Portugal in 2009 - second level of disaggregation: by age group and economic activity

10. SAM of Portugal in 2009, with disaggregated factors of production, the (domestic) institutions' current and capital accounts and the households' current account by main source of income (recipients of pensions and others)

11. SDM of Portugal in 2009- third level of disaggregation: by age group, economic activity and market participation

12. SAM of Portugal in 2009, with disaggregated factors of production (formal and informal labour), the (domestic) institutions' current and capital accounts and the households' current account by main source of income (formal and informal)

13. Percentage changes in macroeconomic aggregates in the three scenarios of possible increases in informal aspects of the activity of Portugal in 2009 
Approach to the socio-economic activity of countries with a Social Accounting Matrices supported by Socio-Demographic Matrices. An application to Portugal. SSantos

\section{Introduction}

SAMs are tools that have specific features for studying the socio-economic activity of countries. Such features allow for the reading and interpretation of the reality under study, leading to the production of an empirical work that is not only capable of highlighting specific aspects of that activity, but also offers the chance to experiment with different interventions in regard to its functioning. A presentation will be made of a proposal for a basic SAM, together with an explanation of possible alternative taxonomies, showing how SAMs can be used as an alternative support for studies being undertaken in several areas, as well as for the work of those taking part in the policy decision process.

By stating that our knowledge of the activity of countries involves the use of national and demographic accounts, Section 2 justifies the decision to use the national and the demographic accounts, as well as the matrix form for studying the empirical evidence of that same activity.

Section 3 adopts a methodological framework based on the works of Richard Stone and Graham Pyatt, outlining the main features of the SAM-based approach, according to which the SAM can describe the activity of countries either empirically or theoretically, depending on whether it is presented in a numerical or an algebraic version, respectively. In keeping with the conclusions outlined in the latest work by Pyatt and Round, stress will be placed on the recommendation for "the design and the construction of SAMs prior to their use in modelling” (Pyatt\& Round, 2012: 272).

Adopting the above-mentioned methodological framework, and based on the latest version of the System of National Accounts (2008 SNA), Section 4 presents a proposal for a SAM structure, beginning with a basic structure and then showing its potentialities for further development. Firstly, Section 4.1 presents a basic structure and emphasises the need to ensure its consistency with the whole system. Such emphasis is then reinforced through the analysis of possible disaggregations and extensions to that basic structure (Section 4.2). Section 4.3 discusses the different forms of analysis made possible by the use of aggregates, indicators and balancing items that can be calculated from such a version and which lie outside the matrix format. In order to test the feasibility of adopting this proposal for different countries, an application is made of the construction of a numerical SAM to Portugal.

In turn, following the methodological framework introduced by Section 3, Section 5 presents the SDM-based approach and a SDM structure, beginning with a standard structure (as proposed by Richard Stone), and then showing possibilities for further developments. In keeping with what was done in Section 4, an application is made of the construction of a numerical SDM for Portugal. 
Approach to the socio-economic activity of countries with a Social Accounting Matrices supported by Socio-Demographic Matrices. An application to Portugal. SSantos

Using the example of an application to Portugal, Section 6 shows how those approaches can be used as an alternative support for studying the socioeconomics of ageing (Section 6.1) and the informal aspects of the activity of countries (Section 6.2) at a macroeconomic level, as well as for the work of those involved in the policy decision process.

A summary and some concluding remarks will be made in Section 7.

\section{Looking for empirical evidence about the activity of countries}

Statistics record facts. The activity of a country is a series of facts. Therefore, any attempt to gain knowledge of those facts calls for the use of statistics. However, the complexity of such activity and the innumerable facts and statistics that serve to record it frequently make this task rather difficult, and sometimes render our efforts unfeasible. The challenge lies in defining the best hierarchy of facts, identifying the correct network of linkages between them, ensuring the availability of statistics and making use of good working tools. Those working tools should enable us to read the reality under study and to produce an empirical work that is not only capable of highlighting specific aspects of that activity, but also offers the chance to simulate different interventions in regard to its functioning. In his preface to the book "Understanding National Accounts”, Giovannini, E. states: “(...) today's national accounts are the core of a modern system of economic statistics, and they provide the conceptual and actual tool to bring coherence to hundreds of statistical sources available in developed countries" (Lequiller F., Blades D., 2006: 3). If we accept the truthfulness of this statement, then a plausible statistical base source of information for studying the part of the activity of a country that can be expressed in currency units ought to be its national accounts. But such activity also depends greatly on the population of that country, whose movements are expressed in terms of human beings. The base source for this latter information will therefore be the demographic accounts, more commonly known as demographic statistics. This methodology can also be applied to countries that are not normally considered to be developed, but which nonetheless seek to produce national accounts. However, although this is not so evident with the demographic accounts, we should bear in mind that underlying the national accounts is a system that defines which facts should be observed and how these same facts should be recorded. The existence of such a system will certainly influence the challenge outlined above. Even so, we will adopt the national accounts as our starting point.

On the other hand, working with the (national and demographic) accounts in a matrix format can be seen as a convenient way of considering the above-mentioned network of linkages existing between facts about the activity of countries, which will thus help us to achieve greater analytical content. The matrix format will also allow for the use of matrix algebra in possible mathematical treatments 
associated with the above-mentioned empirical work, enabling us to experiment with different interventions in regard to the functioning of reality. Some other advantages to be gained from the use of the matrix format will be identified below.

In looking for empirical evidence about the activity of countries, our proposal for a SAM will therefore make use of the specific hierarchy of the facts that are supposedly observed through the system of national accounts. In order to better achieve the same purpose, a SDM that makes use of the hierarchy of the facts observed through the demographic accounts will also be proposed. This will make it possible to identify networks of linkages that can be worked upon with different purposes in mind, always operating within a macro framework. Based upon that work, which exhaustively explores the features of the national accounts and their underlying system, as well as those of the demographic accounts, further work can be carried out, discovering alternative hierarchies of facts, identifying the existence and importance of the non-observed facts, and criticising the way in which the observed facts are recorded, etc.

As the behaviour of facts is explained by theories, our empirical work will also allow us to either test or better define these theories.

\section{The SAM-based approach}

Richard Stone and Graham Pyatt played a key role in the implementation of the SAM-based approach. Both worked on the conceptual details of that approach: the former worked more in numerical terms, within the framework of a system of national accounts, while the latter worked more in algebraic terms, mainly under the scope of input-output analysis. Their work has been decisive for understanding the importance of the SAM as a measurement tool.

In the foreword to the book that can now be regarded as a pioneering work in terms of the SAMbased approach, "Social Accounting for Development Planning with special reference to Sri Lanka", Stone stated that the framework of the system of national accounts can be rearranged and "the entries in a set of accounts can be presented in a matrix in which, by convention (...), incomings are shown in the rows and outgoings are shown in the columns; and in which, reflecting the fact that accounts balance, each row sum is equal to the corresponding column sum". That matrix, with an equal number of rows and columns, is the SAM, in the construction of which "it may be possible to adopt a hierarchical approach, first adjusting the entries in a summary set of national accounts and then adjusting subsets of estimates to these controlling totals". (Pyatt and Roe, 1977: xix, xxiii).

In turn, in the abstract to his article "A SAM approach to modeling", Pyatt says: "Given that there is an accounting system corresponding to every economic model, it is useful to make the accounts 
Approach to the socio-economic activity of countries with a Social Accounting Matrices supported by Socio-Demographic Matrices. An application to Portugal. SSantos

explicit in the form of a SAM. Such a matrix can be used as the framework for a consistent dataset and for the representation of theory in what is called its transaction form". In that transaction form (or TV (transaction value) form), the SAM can be seen “(...) as a framework for theory" and its cells “(...) can be filled instead with algebraic expressions, which describe in conceptual terms how the corresponding transaction values might be determined". Thus, the SAM is used as "the basic framework for model presentation". (Pyatt, 1988: 327; 337).

Looking at the question from the perspectives outlined above, it can be said that a SAM can have two versions: a numerical version, which describes the activity of a country empirically; and an algebraic version, which describes that same activity theoretically. In the former version, each cell has a specific numerical value, with the sums of the rows being equal to the sums of the columns. In the latter version, each cell is filled with algebraic expressions that, together with those of all the other cells, form a SAM-based model, the calibration of which involves a replication of the numerical version. In the words of Pyatt, "the essence of (...) the SAM approach to modelling is to use the same SAM framework for both the empirical and the theoretical description of an economy". (Pyatt, 1988: 337). In 1953, with the first and most fundamental contribution written by Stone, the United Nations recommended the System of National Accounts (SNA), which continued to be published in successive versions until 2008. Also working on the last two versions of that system, published in 1993 and 2008, were, besides the United Nations, the International Monetary Fund, the World Bank, the Organisation for Economic Cooperation and Development and the Statistical Office of the European Communities (Eurostat). Together, they formed the Inter-Secretariat Working Group on National Accounts (ISWGA).

This system establishes the rules for measuring the activity of countries or groups of countries, which, in turn, have been adopted and adapted to specific realities by the corresponding statistical offices. The construction of algebraic versions (or SAM-based models) can be seen, among others, in Pyatt (2001; 1988), Pyatt and Roe (1977), Pyatt and Round (1985; 2012) and Santos (2010; 2009).

In their latest article, Pyatt and Round (2012) explore and derive conditions for a phenomenon that they identify as distributional invariance within a SAM-based model. That phenomenon, which they also call "the Stone phenomenon", is associated with the study of a component of the multiplier effects identified during research into the interrelationship between the structure of production and the distribution of income in the context of economic development. The implications of those conditions were identified by the authors in the design of SAMs and in the consequent quality of results generated via subsequent modelling. Consequently, they conclude by appealing for renewed 
efforts to be made in the design and construction of SAMs with a view to obtaining a more realistic starting point for subsequent modelling.

The SAMs used in the works of reference written about the SAM-based approach were constructed to deal with specific realities. They were created by teams with access to primary sources of information, and were designed according to each specific case. However, there are many cases in which the SAM-based approach is adequate for proceeding with certain studies, even when access to primary sources of information is not feasible and teams are not available. In view of these circumstances, special attention has been paid by the author to the construction of numerical versions of SAMs from the SNA, a subject which will be examined below.

\section{Constructing numerical versions of SAMs from the SNA}

The latest versions of the SNA have devoted a number of paragraphs to discussing the question of SAMs. The 2008 version mentions SAMs in Section D of its Chapter 28, entitled "Input-output and other matrix-based analysis" (ISWGNA, 2009: 519-522), in which a matrix representation is presented of the accounts identified and described in the whole SNA. This representation is not, however, to be identified with the SAM presented in this paper, although they both cover practically all the flows recorded by those accounts.

In turn, the European System of National and Regional Accounts in the European Union of $2010^{1}$ (the adaptation for Europe of the 2008 version of the SNA) makes a reference to the SAM, stating that, among other features, it can be thought of as an expanded system of labour (satellite) accounts (Chapter 22).

The SAM that will be presented below results from the work that the author has undertaken within the methodological framework presented in Section 3, based especially on the works of Graham Pyatt and his associates (Pyatt, 1988 and 1991; Pyatt and Roe, 1977; Pyatt and Round, 1985 and 2012), as well as from the efforts made to reconcile that framework with what has been defined by (the successive versions of) the SNA (Pyatt, 1985 and 1991a; Round, 2003; Santos, 2009). Thus, the author will propose a version of the SAM that seeks to be as exhaustive as possible regarding the flows observed by the SNA. Pyatt (1999) and Round (2003) also approach this same issue with the use of their own versions.

\footnotetext{
${ }^{1}$ EU Regulation No. 549/2013 of the European Parliament and of the European Council of 21 May 2013, on the European system of national and regional accounts in the European Union - Official Journal of the European Union, L174, Volume 56, 26 June 2013.
} 
Approach to the socio-economic activity of countries with a Social Accounting Matrices supported by Socio-Demographic Matrices. An application to Portugal. SSantos

The following proposal will be accompanied by the applications made of the SAM to Portugal in 2009. In that year, the Portuguese national accounts adopted the European System of National and Regional Accounts in the European Community of 1995 - the adaptation for Europe of the 1993 version of the SNA. Because the general differences between the accounts identified in those applications and described in the 1993 and 2008 versions of the SNA are not significant, they will be used to illustrate the following exposition.

Thus, returning to the description provided in Section 3, a square matrix will be worked upon, in which the sum of the rows is equal to the corresponding sum of the columns. In keeping with what is conventionally accepted, and after some adjustments have been made to adapt this to the SNA, resources, incomes, receipts or changes in liabilities and net worth will be represented in the entries made in the rows, while uses, outlays, expenditures or changes in assets will be represented in the entries made in the columns. Each flow will therefore be recorded only once, in a cell of its own. The following description will be made in accordance with the 2008 SNA.

The starting point for the construction of a numerical SAM should be its design, i.e. the classification or taxonomy of its accounts. That taxonomy and the levels of disaggregation adopted will depend on the purposes for which the SAM is to be used, as well as on the way that the available information is organised. Adopting the national accounts as the base source of information, a basic structure is proposed below, which takes into account the underlying SNA and highlights the consistency of the whole system. The flexibility of that basic structure will be shown, together with the possibilities that it presents for characterising problems and for achieving specific purposes. These will also be seen as possibilities for going beyond the SNA, which is considered as a starting point, as mentioned in Section 2.

In this respect, we are aware of the dangers associated with the adoption of international standards and systems of classification and their failure to recognise important issues and realities. This problem is also mentioned by Pyatt and Round when they consider the choice of taxonomies within a SAM framework and the strategic influence that these can have on the potential usefulness of subsequent applications. According to those authors: "the taxonomies that are embedded within [the SAM framework] predetermine what any subsequent modelling exercise might have to say in response to specific distributional questions" (Pyatt and Round, 2012: 270).

\subsection{The SAM's basic structure and its consistency with the whole system}

Adopting the working method recommended by Stone in the second paragraph of Section 3 of this paper, the basic structure for the SAM presented here will be a summary set of the national accounts 
Approach to the socio-economic activity of countries with a Social Accounting Matrices supported by Socio-Demographic Matrices. An application to Portugal. SSantos

and the controlling totals for the other levels of disaggregation, which will later be analysed in Section 4.2. Thus, in keeping with the conventions and nomenclatures defined by the SNA, besides a rest of the world account, the proposed SAM will also include both production and institutional accounts.

Table 1 shows the above-mentioned basic structure, representing the nominal transactions ("t") with which two indexes are associated. The location of these transactions within the matrix framework is described by those indexes, the first of which represents the row account while the second represents the column account. Each cell of this matrix will be converted into a submatrix, with the number of rows and columns corresponding to the level of disaggregation of the row and column accounts. This same table also identifies blocks, which are submatrices or sets of submatrices with common characteristics. The specification of these blocks will be made below and involves an identification of the flows of the National Accounts, which will continue to be the same even if some disaggregation is performed - thereby preserving the consistency of the whole system.

Table 1. The Basic SAM by blocks

\begin{tabular}{|c|c|c|c|c|c|c|c|c|}
\hline & $\mathrm{p}$ & $a$ & $\mathrm{f}$ & dic & dik & dif & rw & total \\
\hline $\mathrm{p}$ - products & $\begin{array}{l}\text { TTM } \\
\left(t_{p, p}\right)\end{array}$ & $\begin{array}{c}\mathrm{IC} \\
\left(\mathrm{t}_{\mathrm{p}, a}\right)\end{array}$ & 0 & $\begin{array}{c}\mathrm{FC} \\
\left(\mathrm{t}_{\mathrm{p}, \mathrm{dic}}\right)\end{array}$ & $\begin{array}{c}\mathrm{GCF} \\
\left(\mathrm{t}_{\mathrm{p}, \mathrm{dik}}\right)\end{array}$ & 0 & $\begin{array}{c}\mathrm{EX} \\
\left(\mathrm{t}_{\mathrm{p}, \mathrm{rw}}\right)\end{array}$ & $\begin{array}{l}\mathrm{AD} \\
\left(\mathrm{t}_{\mathrm{p} .}\right)\end{array}$ \\
\hline$a$ - activities & $\begin{array}{c}\mathrm{P} \\
\left(\mathrm{t}_{a, \mathrm{p}}\right)\end{array}$ & 0 & 0 & 0 & 0 & 0 & 0 & $\begin{array}{l}\mathrm{VPT} \\
\left(\mathrm{t}_{a \cdot}\right)\end{array}$ \\
\hline$f$ - factors & 0 & $\begin{array}{c}\text { CFP_GAV } \\
\left(\mathrm{t}_{\mathrm{f}, a}\right)\end{array}$ & 0 & 0 & 0 & 0 & $\begin{array}{l}\text { CFP } \\
\left(\mathrm{t}_{\mathrm{f}, \mathrm{rw}}\right) \\
\end{array}$ & $\begin{array}{c}\text { AFIR } \\
\left(\mathrm{t}_{\mathrm{f} .}\right)\end{array}$ \\
\hline $\begin{array}{l}\text { dic }- \text { (domestic) institutions' } \\
\text { current account }\end{array}$ & $\begin{array}{c}\text { NTP } \\
\left(t_{\text {dic }, p}\right)\end{array}$ & $\begin{array}{c}\text { NTA } \\
\left(\mathrm{t}_{\mathrm{dic}, a}\right)\end{array}$ & $\begin{array}{c}\text { CFP_GNI } \\
\left(t_{\text {dic }, f}\right)\end{array}$ & $\begin{array}{c}\mathrm{CT} \\
\left(\mathrm{t}_{\text {dic,dic }}\right)\end{array}$ & 0 & 0 & $\begin{array}{c}\mathrm{CT} \\
\left(\mathrm{t}_{\mathrm{dic}, \mathrm{rw}}\right)\end{array}$ & $\begin{array}{c}\mathrm{AI} \\
\left(\mathrm{t}_{\mathrm{dic}}\right)\end{array}$ \\
\hline $\begin{array}{l}\text { dik - (domestic) institutions' } \\
\text { capital account }\end{array}$ & 0 & 0 & 0 & $\begin{array}{c}\mathrm{S} \\
\left(\mathrm{t}_{\text {dik,dic }}\right)\end{array}$ & $\begin{array}{c}\mathrm{KT} \\
\left(\mathrm{t}_{\text {dik,dik }}\right)\end{array}$ & $\begin{array}{c}\mathrm{NLB} \\
\left(\mathrm{t}_{\mathrm{dik}, \mathrm{dif}}\right)\end{array}$ & $\begin{array}{c}\mathrm{KT} \\
\left(\mathrm{t}_{\mathrm{dik}, \mathrm{rw}}\right)\end{array}$ & $\begin{array}{l}\text { INVF } \\
\left(t_{\text {dik. }}\right)\end{array}$ \\
\hline $\begin{array}{l}\text { dif - (domestic) institutions' } \\
\text { financial account }\end{array}$ & 0 & 0 & 0 & 0 & 0 & $\begin{array}{c}\text { FT } \\
\left(\mathrm{t}_{\mathrm{dif}, \mathrm{dif}}\right)\end{array}$ & $\begin{array}{c}\text { FT } \\
\left(t_{\text {dif,rw }}\right)\end{array}$ & $\begin{array}{l}\text { TFTR } \\
\left(\mathrm{t}_{\text {dif. }}\right)\end{array}$ \\
\hline rw - rest of the world & $\begin{array}{c}\text { IM\&NTP } \\
\left(\mathrm{t}_{\mathrm{rw}, \mathrm{p}}\right)\end{array}$ & $\begin{array}{l}\text { NTA } \\
\left(\mathrm{t}_{\mathrm{rw}, a}\right) \\
\end{array}$ & $\begin{array}{l}\text { CFP } \\
\left(t_{r w, f}\right)\end{array}$ & $\begin{array}{c}\mathrm{CT} \\
\left(\mathrm{t}_{\mathrm{rw}, \mathrm{dic}}\right)\end{array}$ & $\begin{array}{c}\mathrm{KT} \\
\left(\mathrm{t}_{\mathrm{rw}, \mathrm{dik}}\right) \\
\end{array}$ & $\begin{array}{c}\text { FT } \\
\left(\mathrm{t}_{\mathrm{rw}, \mathrm{dif}}\right)\end{array}$ & 0 & $\begin{array}{c}\text { TVRWP } \\
\left(\mathrm{t}_{\mathrm{ww} .}\right)\end{array}$ \\
\hline total & $\begin{array}{l}\text { AS } \\
\left(\mathrm{t}_{\mathrm{p}}\right)\end{array}$ & $\begin{array}{l}\mathrm{VCT} \\
(\mathrm{t} . a) \\
\end{array}$ & $\begin{array}{c}\text { AFIP } \\
\left(t_{\text {.f }}\right)\end{array}$ & $\begin{array}{l}\text { AIP } \\
\left(\mathrm{t}_{\text {dic }}\right)\end{array}$ & $\begin{array}{c}\text { AINV } \\
\left(\mathrm{t}_{\text {.dik }}\right)\end{array}$ & $\begin{array}{l}\text { TFTP } \\
\left(\mathrm{t}_{\text {.dif }}\right)\end{array}$ & $\begin{array}{c}\text { TVRWR } \\
\left(\mathrm{t}_{\mathrm{rw}}\right)\end{array}$ & \\
\hline
\end{tabular}

Source: Santos $(2009 ; 2010)$

Note: The first three accounts ( $\mathrm{p}=$ products (or goods and services), $a=$ activities (or industries) and $\mathrm{f}=$ factors (of production)) are the production accounts of the economy and the next three accounts $($ dic $=$ current; dik = capital; dif $=$ financial $)$ are the accounts of the (domestic) institutions. The last account ( $\mathrm{rw}=$ rest of the world) represents the "outside" part of the (domestic) economy.

Description of the blocks (included in the texts are letters followed by numbers between brackets, which are the flow codes of the National Accounts, in accordance with the 2008 SNA): 
a) Production - $\mathrm{P}$ (cell: $\mathrm{t}_{a, \mathrm{p}}$; basic prices) - represents the output of goods and services (P1).

b) Domestic Trade is represented by the value of domestically transacted products, which can be either domestically produced or imported.

b.1) Intermediate Consumption - IC (cell: $\mathrm{t}_{\mathrm{p}, a}$; purchasers' prices) - consists of the value of the goods and services consumed as inputs by a process of production, excluding those fixed assets whose consumption is recorded as consumption of fixed capital (P2).

b.2) Final Consumption - FC (cell: $t_{\text {pdic }}$; purchasers' prices) - consists of the expenditure incurred by resident institutional units on goods or services that are used for the direct satisfaction of individual needs or wants, or the collective needs of members of the community (P3).

b.3) Gross Capital Formation - GCF (cell: t $\mathrm{p}_{\mathrm{pdik}}$; purchasers' prices) - includes gross fixed capital formation, changes in inventories, and acquisitions less disposals of valuables (P5).

c) External Trade includes the transactions in goods and services from non-residents to residents, also known as imports (P7), or IM (cell: trw,p; purchasers' prices), and the transactions in goods and services from residents to non-residents, also known as exports (P6), or EX (cell: $\mathrm{t}_{\mathrm{p}, \mathrm{rw}}$; purchasers' prices).

d) Trade and Transport Margins - TTM (cell: $t_{p, p}$ ) - amounts to zero and, when it is disaggregated and takes the form of a submatrix, it allocates the output of the trade and transport services used in the domestic trade to the supplied products.

e) Net taxes on production and imports

e.1) Net Taxes on Production - NTA (cells: $\mathrm{t}_{\mathrm{dic}, a} ; \mathrm{t}_{\mathrm{rw}, a}$ ) - represents the (other) taxes on production (D29) minus the (other) subsidies to production (D39).

e.2) Net Taxes on Products - NTP (cells: $\left.t_{d i c, p} ; t_{r w, p}\right)$ - represents the taxes on products (D21) minus the subsidies on products (D31).

f) Compensation of Factors of Production - CFP (cells: $t_{f, a} ; t_{d i c, f} ; t_{f, r w} ; t_{r w, f}$ ) - consists of the income of the institutional sectors originating from the compensation of employees (D1) and the compensation of employers and own-account (or self-employed) workers, and the compensation of capital, including property income (D4; B2g-B3g). The functional distribution is represented by the Gross Added Value - GAV (cell: $\mathrm{t}_{\mathrm{f}, a}$ ), whereas the institutional distribution is represented by the Gross National Income - GNI (cell: $\mathfrak{t}_{d i c, f}$ ). 
g) Current Transactions - CT (cells: $\left.\mathrm{t}_{\text {dic,dic }} ; \mathrm{t}_{\mathrm{dic}, \mathrm{rw}} ; \mathrm{t}_{\mathrm{rw}, \mathrm{dic}}\right)$ - includes: current taxes on income, wealth, etc. (D5); net social contributions (D61); social benefits other than social transfers in kind (D62); other current transfers (D7); and the adjustment made for the change in pension entitlements (D8).

h) Capital Transactions - KT (cells: $t_{\text {dik,dik }}$; $t_{d i k, r w ;} t_{r w, d i k}$ - includes: capital taxes (D91); investment grants (D92); other capital transfers (D99); and acquisitions less disposals of non-financial nonproduced assets (NP1-3).

i) Financial Transactions - FT (cells: $t_{\text {dif,dif }}$; $\left.t_{\text {dif,rw }} ; t_{r w, d i f}\right)$ - includes: monetary gold and special drawing rights (F1); currency and deposits (F2); debt securities (F3); loans (F4); equity and investment fund shares (F5); insurance, pension and standardised guarantee schemes (F6); financial derivatives and employee stock options (F7); and other accounts receivable/payable (F8).

j) Gross Saving - $S$ (cell: $t_{\text {dik,dic }}$ ) - measures the portion of aggregate income that is not used for final consumption expenditure and current transfers to domestic institutions or to the rest of the world (B9g).

k) Net Borrowing/Lending - NLB (cell: $t_{\text {dik,dif }}$ )

The net lending or borrowing of the total economy is the sum of the net lending or borrowing of the institutional sectors. It represents, respectively, the net resources that the total economy makes available to the rest of the world or the net resources that it receives from the rest of the world to finance the corresponding needs of investment funds (B9).

Here, those amounts are recorded in the row(s) of the capital account, i.e. as changes in liabilities and net worth, and in the column(s) of the financial account, i.e. as changes in assets. This is why the mathematical signs of this item have been changed in relation to the SNA.

The construction of a SAM is easier when it is performed by blocks.

The totals of each account represent the corresponding sums of the cells in rows and in columns, with the following description:

I. Products account (p): Aggregate Demand - AD, the row sum (cell: $t_{\mathrm{p} .}$ ); Aggregate Supply - AS, the column sum (cell: t.p).

II. Activities account $(a)$ : Production Value - VPT, the row sum (cell: $\mathrm{t}_{a}$ ); Total Costs - VCT, the column sum (cell: t.a). 
III. Factors of Production (f): Aggregate Factors Income (Received) - AFIR, the row sum (cell: $\mathbf{t}_{\mathrm{f}}$ ); Aggregate Factors Income (Paid) - AFIP, the column sum (cell: t.f).

IV. Current account of (domestic) institutions (dic): Aggregate Income (received) - AI, the row sum (cell: $t_{\text {dic. }}$ ); Aggregate Income (Paid) - AIP, the column sum (cell: t.dic).

V. Capital account of (domestic) institutions (dik): Investment Funds - INVF, the row sum (cell: $\mathrm{t}_{\text {dik. }}$ ); Aggregate Investment - AINV, the column sum (cell: $\mathrm{t}_{\text {.dik }}$ ).

VI. Financial account of (domestic) institutions (dif): Total Financial Transactions (Received) TFTR, the row sum (cell: $t_{\text {dif. }}$ ); Total Financial Transactions (Paid) - TFTP, the column sum (cell: t.dif).

VII. Rest of the world account (rw): Value of Transactions to the Rest of the World (Paid) - TVRWP, the row sum (cell: $\mathrm{t}_{\mathrm{rw}}$ ); Value of Transactions from the Rest of the World (Received) - TVRWR, the column sum (cell: $t$.rw).

From the above description, two further advantages of the matrix presentation of the national accounts can be highlighted: each transaction represents a single entry and can be characterised by its position; each account is represented by a row and a column, whose balance is ensured by the equality of their sums.

The Integrated Economic Accounts Table is equivalent to a summary of what is observed by the SNA. According to the 2008 SNA: "The integrated economic accounts use (...) three of the conceptual elements of the SNA (...) [institutional units and sectors, transactions, and assets and liabilities] together with the concept of the rest of the world to form a wide range of accounts. These include the full sequence of accounts for institutional sectors, separately or collectively, the rest of the world and the total economy.... This table shows, simultaneously, the general accounting structure of the SNA and presents a set of data for the institutional sectors, the economy as a whole and the rest of the world" (ISWGNA, 2009: 23; 29). Based on this table and the previous description (adapted to the previous version of the SNA), it was possible to construct the basic SAM presented in Table 2, representing the highest possible level of aggregation of the activity of Portugal observed by the national accounts in 2009.

Considering the description given about Table 1, and based on the reading of the products account in Portugal in 2009, represented in Table 2 - row and column p, the main components of the aggregate demand and supply of the goods and services transacted in the market and captured by the Portuguese National Accounts, can be identified in millions of euros. Thus, reading in rows, the total aggregate demand of 390,882 million euros was composed of 162,661million euros of intermediate 
Approach to the socio-economic activity of countries with a Social Accounting Matrices supported by Socio-Demographic Matrices. An application to Portugal. SSantos

consumption, 146,934 million euros of final consumption, and 34,051 million euros of gross capital formation and 47,236 million euros of exports. Reading in columns, the total aggregate supply of 390,882 million euros (equal to the total aggregate demand) was composed of 311,365 million euros from the output of goods and services, 19694 million euros of net taxes on products received by the Portuguese Government and 59,717 million euros of imports and 106 million euros of net taxes on products sent to the institutions of the European Union. A similar reading can be made for each of the other columns and rows of Table 2 for Portugal.

Table 2. Basic SAM of Portugal in 2009

\begin{tabular}{|c|c|c|c|c|c|c|c|c|}
\hline \multicolumn{9}{|c|}{ (Unit: $10^{6}$ euros) } \\
\hline & $\mathrm{p}$ & $a$ & $\mathrm{f}$ & dic & dik & dif & rw & total \\
\hline $\mathrm{p}$ - products & 0 & 162661 & & 146934 & 34051 & & 47236 & 390882 \\
\hline$a-$ activities & 311365 & & & & & & & 311365 \\
\hline $\mathrm{f}-$ factors & & 149403 & & & & & 9039 & 158443 \\
\hline $\begin{array}{l}\text { dic }-(\text { domestic }) \text { institu- } \\
\text { tions' current account }\end{array}$ & 19694 & 522 & 141423 & 85711 & & & 4581 & 251931 \\
\hline $\begin{array}{r}\text { dik - (domestic) institu- } \\
\text { tions' capital account }\end{array}$ & & & & 15865 & 1536 & 16222 & 2232 & 35856 \\
\hline $\begin{array}{c}\text { dif }-(\text { domestic }) \text { institu- } \\
\text { tions' financial account }\end{array}$ & & & & & & 36659 & 37209 & 73868 \\
\hline rw - rest of the world & $59823^{\text {(a) }}$ & -1222 & 17019 & 3421 & 268 & 20987 & & 100297 \\
\hline total & 390882 & 311365 & 158443 & 251931 & 35856 & 73868 & 100297 & \\
\hline
\end{tabular}

Sources: Statistics Portugal (INE); Portuguese Central Bank (Banco de Portugal).

(a) 59717 (imports) +106 (net taxes on products sent to the institutions of the European Union)

Therefore, as mentioned above, and again using the words of Stone, the basic SAM that has just been described can be considered as the most aggregate "summary set of national accounts", representing a first level of the intended hierarchical method, with all the controlling totals for the next level of that hierarchy. From here the consistency of the whole (supposedly) observed system can be ensured. From the above description, two further advantages of the matrix presentation of the national accounts can be highlighted: each transaction represents a single entry and can be characterised by its position; each account is represented by a row and a column, whose balance is ensured by the equality of their sums. 
Approach to the socio-economic activity of countries with a Social Accounting Matrices supported by Socio-Demographic Matrices. An application to Portugal. SSantos

\subsection{Disaggregations and extensions}

Since the national accounts cover all the details covered by the basic structure presented above, some other levels of the above mentioned-hierarchical method can be identified within the national accounts, providing other controlling totals for greater levels of disaggregation. As will be seen below, this disaggregation can be made at the levels of the production, institutional and rest of the world accounts, either within the scope of the SNA conventions or not. Reverse reasoning can be applied to the case of aggregation. Therefore, in addition to the already-mentioned advantages of presenting the national accounts in the form of a matrix, it is also possible to make an easier aggregation and disaggregation of the accounts, in accordance with the specific requirements of the exercise and the available information, without losing the consistency of the system.

In the words of Round, in his Foreword to Santos (2009): “The key to constructing a useful SAM and developing an effective SAM-based model is the SAM design. A SAM need not be dimensionally large as long as it represents the most significant features of economy-wide interdependence. More precisely, this means designing the SAM so that the key sectors, markets and institutions are as fully represented as is practicable. Estimation of the transactions between accounts is obviously also important but this needs to go in tandem with the SAM design" (Santos, 2009: xiv).

It is also worth mentioning that, although the quarterly national accounts are not as complete as the annual ones, it will nonetheless be possible to make some further disaggregations from these accounts in terms of time.

Furthermore, disaggregations can be made in terms of space, since regional accounts are also considered. In that case, it is possible to work with regions and countries, either individually or as a group. Round (1991; 1994), for example, experimented with the case of Europe. It would even be possible to think in world terms, if the SNA could be adopted worldwide.

Extensions are also possible, either from the national accounts or from other sources of information, with the convenient adjustment to, or connection with, the whole system in order to maintain its consistency.

The 2008 SNA dedicates its Chapter 29 to "Satellite accounts and other extensions" (ISWGNA, 2009: $523-544)^{2}$, where the main idea is to serve specific analytical purposes, in a way that is consistent with the central framework, although not fully integrated into it (ISWGNA, 2009: 37-38). In this respect, the author would like to support Steven Keuning and Willem Ruijter's idea of a “complete

\footnotetext{
${ }^{2}$ The 2010 ESA dedicates its Chapter 22 to that same subject (see footnote 1).
} 
Approach to the socio-economic activity of countries with a Social Accounting Matrices supported by Socio-Demographic Matrices. An application to Portugal. SSantos

data set" which "could be tentatively labelled: a System of Socio-economic Accounts" (Keuning and Ruijter, 1988: 73).

\section{a) Production accounts}

In the basic structure proposed in Section 4.1, the production accounts are the accounts of products, activities and factors of production. These accounts correspond respectively to the SNA accounts of goods and services, production and the primary distribution of income. Thus, within these accounts and depending on the available level of disaggregation, it can be seen how the available products are used, with some details being provided about the process of production and about the way in which the incomes resulting from that process and the ownership of assets are distributed among institutions and activities.

The SNA uses the Central Product Classification (CPC) Version 2 (completed in December 2008) to classify products (ISWGNA, 2009: 19), which are organised into 10 sections, with it being possible to go as far as the fifth level of disaggregation within each of these.

In turn, the International Standard Industrial Classification of All Economic Activities (ISIC) Revision 4 (officially released in August 2008) is used to classify activities (ISWGNA, 2009: 20), organised into 23 sections, the disaggregation of which is perfectly consonant with that of the product classification. The Supply and Use Table provides this information, usually at an intermediate level of disaggregation.

As described above, in the characterisation of the block representing the compensation of the factors of production, the disaggregation that can be made from the already mentioned tables of the national accounts is between labour (or the compensation of employees) and what has been referred to as the compensation of other factors, which includes the compensation of employers and own-account (or self-employed) workers, and the compensation of capital, namely property income. Such information can only be derived from the Integrated Economic Accounts Table if the products and activities accounts are not disaggregated, or from the Supply and Use Table if those same accounts are disaggregated. Table 3, which contains the above-mentioned application to Portugal, in which the products and activities accounts are not disaggregated, presents the possible disaggregation of the factors of production accounts based on the Integrated Economic Accounts Table.

Regarding the design of SAMs and in order to establish a connection between the taxonomies dealt with in this section and in the next, it should be mentioned that in their latest work, besides a rest of the world account, Pyatt and Round identify accounts for goods and non-factor services and factor services, as well as, accounts for institutions. In the latter, they identify private and public sector 
Approach to the socio-economic activity of countries with a Social Accounting Matrices supported by Socio-Demographic Matrices. An application to Portugal. SSantos

current accounts and combined capital accounts. About this classification, they say the following: "taxonomies for goods and services serve to distinguish different markets and should therefore be constructed in ways that recognise significant market failures and segmentation. In contrast, the institutions within the private sector are differentiated by the assets they own (or do not own...) and the productive activities they are responsible for.... Factors of production and the assets that provide them are therefore the defining feature of institutions." (Pyatt and Round, 2012: 268).

\section{b) Institutions and rest of the world accounts}

In the basic structure proposed in Section 4.1, the domestic institutions are divided into current, capital and financial accounts. These accounts correspond, respectively, to the following SNA accounts: secondary distribution of income, redistribution of income in kind and use of income; capital; and financial accounts. Within these accounts, depending on the level of disaggregation available, the current accounts show how the national income is transformed into disposable income through the receipt and payment of current transfers, and how the latter is distributed between final consumption and saving. In turn, the capital account records the transactions linked to acquisitions of non-financial assets and capital transfers involving the redistribution of wealth, whereas the financial account records the transactions in financial assets and liabilities between institutional units, and between these and the rest of the world.

All the linkages between the domestic economy and the rest of the world, i.e. all the transactions between resident and non-resident units, are recorded both in the SAM and in the SNA through the rest of the world account.

Chapter 4 of the 2008 SNA specifies the institutional sectors, including the rest of the world, and their possible disaggregation, which in some cases can be taken as far as the third level (ISWGNA, 2009: 61-85), although normally it cannot be taken beyond the first level. In the case of the rest of the world, such disaggregation will certainly depend on the country, or group of countries, that adopt and adapt this system ${ }^{3}$.

At the first level of disaggregation, the accounts of the institutions, as well as the rest of the world account, are part of the Integrated Economic Accounts Table. Higher levels of disaggregation, whenever these are possible, are usually published in the separate accounts of institutions. Even at the first level of disaggregation, any work conducted with the institutional sectors when there are

\footnotetext{
${ }^{3}$ In the case of the 2010 ESA (Chapter 23), a second level of disaggregation is made, with a distinction being drawn between Member States and institutions and bodies of the European Union and non-member countries and international organisations that are not resident in the European Union. For the former, the disaggregation can be made as far as the fourth level (see footnote 1).
} 
Approach to the socio-economic activity of countries with a Social Accounting Matrices supported by Socio-Demographic Matrices. An application to Portugal. SSantos

transactions involving more than one row or column of the SAM also requires the so-called "from whom to whom matrices". These matrices make it possible to fill in the cells of the submatrices of transactions taking place within domestic institutions and between institutions and the rest of the world, recorded in the above-described blocks of current, capital, and financial transactions (Section $4.1 \mathrm{~g}-\mathrm{i})$.

The disaggregation of specific institutional sectors makes it possible to analyse the most diverse aspects of the corresponding roles in the activity of countries (Santos (2004) and (2007) are examples of studies on the role of the general government and its subsectors - central government, local government and social security funds).

The detailed study of the specific accounts of domestic institutions and their corresponding transactions also makes it possible to analyse specific aspects of that same activity: the distribution and redistribution of income, using the current account; the redistribution of wealth, using the capital account; investment, its financing, and the implicit levels of the financing requirements and availability of the institutional sectors and the whole economy, using the capital and financial accounts.

In turn, the rest of the world account can provide many possibilities for studying the international economic relations of the domestic economy.

Table 3 presents the possible disaggregation of the institutions' current and capital accounts, made from the Integrated Economic Accounts Table and the "from whom to whom matrices", for the above-mentioned application. From that table, we can discover a little more about the reality under study - Portugal in 2009. This is the case with the aggregate factors income - the so-called primary distribution of income, to the amount of 158,443 million euros, in which it can now be seen that 86,127 million euros account for the compensation of employees - row and column 3, and 72,315 million euros account for the compensation of other factors of production, namely employers and own-account workers, land and capital (including property income) - row and column 4.

Through row 3 we can see that 85,888 million euros represent the part of the gross added value, generated in the domestic economy by residents and non-residents that is attributed to the compensation of employees, to which are added 239 million euros generated abroad by residents. In turn, row 4 shows that 63,515 million euros represent the part of the gross added value, generated in the domestic economy by residents and non-residents, that is attributed to the above-mentioned other factors of production, to which are added 8,800 million euros generated abroad by residents. Rows 3 and 4 allow for the study of aspects related with the functional distribution of income. 
Through column 3, we can see that 85,757 million euros represent the part of the gross national income, generated in the domestic economy and abroad by residents, that is attributed to the compensation of employees, to which are added 370 million euros generated in the domestic economy by non-residents and sent abroad. In column 4, we can see that 55,666 million euros is the part of the gross national income, generated in the domestic economy and abroad by residents, that is attributed to the compensation of other factors, to which are added 16,649 million euros generated in the domestic economy by non-residents and sent abroad. From the cells of columns 3 and 4, it is possible to study aspects related to the institutional distribution of income. 
Approach to the socio-economic activity of countries with a Social Accounting Matrices supported by Socio-Demographic Matrices. An application to Portugal. SSantos

Table 3. SAM of Portugal in 2009, with disaggregated factors of production and the (domestic) institutions' current and capital accounts

\begin{tabular}{|c|c|c|c|c|c|c|c|c|c|c|c|c|c|c|}
\hline \multirow{2}{*}{\multicolumn{4}{|c|}{ 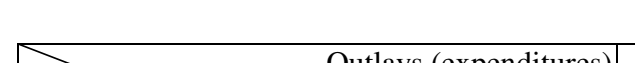 }} & \multirow{2}{*}{\multicolumn{5}{|c|}{ PRODUCTION }} & \multicolumn{6}{|c|}{ (Unit: $10^{6}$ euros) } \\
\hline & & & & & & & & & \multirow{2}{*}{\multicolumn{6}{|c|}{$\begin{array}{c}\text { INSTITUTIONS } \\
\text { CURRENT ACCOUNT }\end{array}$}} \\
\hline & & & & \multirow[b]{2}{*}{ PRODUCTS } & \multirow[b]{2}{*}{ ACTIVITIES } & \multicolumn{3}{|c|}{ FACTORS } & & & & & & \\
\hline & & & & & & $\begin{array}{c}\text { Labour } \\
\text { (employees) }\end{array}$ & Other & Total & Households & $\begin{array}{l}\text { Nonfinancial } \\
\text { corporations }\end{array}$ & $\begin{array}{c}\text { Financial } \\
\text { corporations }\end{array}$ & Government & NPISH & Total \\
\hline \multicolumn{4}{|c|}{ Incomes (receipts) } & 1 & 2 & 3 & 4 & & 5 & 6 & 7 & 8 & 9 & \\
\hline \multirow{5}{*}{ 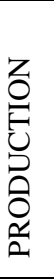 } & \multicolumn{2}{|c|}{ PRODUCTS } & 1 & 0 & 162661 & 0 & 0 & 0 & 106206 & 0 & 0 & 37160 & 3568 & 146934 \\
\hline & \multicolumn{2}{|c|}{ ACTIVITIES } & 2 & 311365 & 0 & 0 & 0 & 0 & 0 & 0 & 0 & 0 & 0 & 0 \\
\hline & \multirow{3}{*}{ 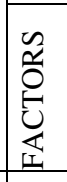 } & Labour (employees) & 3 & 0 & 85888 & 0 & 0 & 0 & 0 & 0 & 0 & 0 & 0 & 0 \\
\hline & & Other & 4 & 0 & 63515 & 0 & 0 & 0 & 0 & 0 & 0 & 0 & 0 & 0 \\
\hline & & Total & & 0 & 149403 & 0 & 0 & 0 & 0 & 0 & 0 & 0 & 0 & 0 \\
\hline \multirow{13}{*}{ 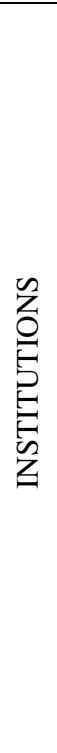 } & \multirow{6}{*}{ 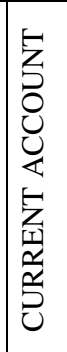 } & Households & 5 & 0 & 0 & 85757 & 34258 & 120015 & 801 & 1830 & 5226 & 28998 & 95 & 36949 \\
\hline & & Nonfinancial corporations & 6 & 0 & 0 & 0 & 14615 & 14615 & 1830 & 0 & 613 & 171 & 0 & $2613 \vdots$ \\
\hline & & Financial corporations & 7 & 0 & 0 & 0 & 5990 & 5990 & 5289 & 519 & 131 & 42 & 32 & 6013 \\
\hline & & Government & 8 & 19694 & 522 & 0 & -34 & -34 & 31224 & 5684 & 671 & 8 & 22 & 37610 \\
\hline & & $\begin{array}{l}\text { NonProfitInstitutionsServing } \\
\text { Households(NPISH) }\end{array}$ & 9 & 0 & 0 & 0 & 837 & 837 & 324 & 154 & 50 & 1997 & 0 & 2525 \\
\hline & & Total & & 19694 & 522 & 85757 & 55666 & 141423 & 39468 & 8187 & 6690 & 31215 & 150 & 85711 \\
\hline & \multirow{6}{*}{ 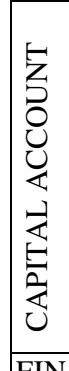 } & Households & 10 & 0 & 0 & 0 & 0 & 0 & 13728 & 0 & 0 & 0 & 0 & 13728 \\
\hline & & Nonfinancial corporations & 11 & 0 & 0 & 0 & 0 & 0 & 0 & 8903 & 0 & 0 & 0 & 8903 \\
\hline & & Financial corporations & 12 & 0 & 0 & 0 & 0 & 0 & 0 & 0 & 5283 & 0 & 0 & 5283 \\
\hline & & Government & 13 & 0 & 0 & 0 & 0 & 0 & 0 & 0 & 0 & -11695 & 0 & -11695 \\
\hline & & \begin{tabular}{|l} 
NonProfitInstitutionsServing \\
Households(NPISH) \\
\end{tabular} & 14 & 0 & 0 & 0 & 0 & 0 & 0 & 0 & 0 & 0 & -354 & -354 \\
\hline & & Total & & 0 & 0 & 0 & 0 & 0 & 13728 & 8903 & 5283 & -11695 & -354 & 15865 \\
\hline & \multicolumn{2}{|c|}{ FINANCIAL ACCOUNT } & 15 & 0 & 0 & 0 & 0 & 0 & 0 & 0 & 0 & 0 & 0 & 0 \\
\hline \multicolumn{3}{|c|}{ REST OF THE WORLD } & 16 & 59823 & -1222 & 370 & 16649 & 17019 & 1345 & 240 & 110 & 1726 & 0 & 3421 \\
\hline \multicolumn{4}{|c|}{ TOTAL } & 390882 & 311365 & 86127 & 72315 & 158443 & 160747 & 17331 & 12082 & 58407 & 3363 & 251931 \\
\hline
\end{tabular}

Sources: Statistics Portugal (INE); Portuguese Central Bank (Banco de Portugal). 
Approach to the socio-economic activity of countries with a Social Accounting Matrices supported by Socio-Demographic Matrices. An application to Portugal. SSantos

Table 3 (continued). SAM of Portugal in 2009, with disaggregated factors of production and the (domestic) institutions' current and capital accounts

\begin{tabular}{|c|c|c|c|c|c|c|c|c|c|c|c|c|}
\hline \multirow{2}{*}{\multicolumn{4}{|c|}{$\widetilde{O}$ Outlays (expenditures) }} & \multirow{2}{*}{\multicolumn{7}{|c|}{ INSTITUTIONS }} & \multirow{4}{*}{$\begin{array}{l}\text { REST OF THE } \\
\text { WORLD }\end{array}$} & \multirow[b]{4}{*}{ TOTAL } \\
\hline & & & & & & & & & & & & \\
\hline & & & & & & CAPITAL AC & COUUNT & & \multirow{3}{*}{ Total } & & & \\
\hline & & & & Households & \begin{tabular}{|l|l|}
$\begin{array}{l}\text { Nonfinancial } \\
\text { corporations }\end{array}$ \\
\end{tabular} & $\begin{array}{c}\text { Financial } \\
\text { corporations }\end{array}$ & Government & NPISH & & FINANCIAL & & \\
\hline \multicolumn{4}{|c|}{ Incomes (receipts) } & 10 & 11 & 12 & 13 & 14 & & 15 & 16 & \\
\hline \multirow{5}{*}{$\begin{array}{l}z \\
0 \\
0 \\
0 \\
\vdots \\
0 \\
0 \\
\frac{\alpha}{2}\end{array}$} & \multicolumn{2}{|c|}{ PRODUCTS } & 1 & 7269 & 19812 & 1064 & 5071 & 834 & 34051 & 0 & 47236 & 390882 \\
\hline & \multicolumn{2}{|c|}{ ACTIVITIES } & 2 & 0 & 0 & 0 & 0 & 0 & 0 & 0 & 0 & 311365 \\
\hline & \multirow{3}{*}{ 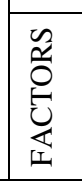 } & Labour (employees) & 3 & 0 & 0 & 0 & 0 & 0 & 0 & 0 & 239 & 86127 \\
\hline & & Other & 4 & 0 & 0 & 0 & 0 & 0 & 0 & 0 & 8800 & 72315 \\
\hline & & \multicolumn{2}{|l|}{ Total } & 0 & 0 & 0 & 0 & 0 & 0 & 0 & 9039 & 158443 \\
\hline \multirow{13}{*}{ 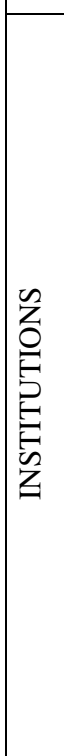 } & \multirow{6}{*}{ 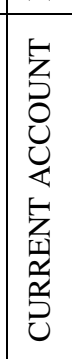 } & Households & 5 & 0 & 0 & 0 & 0 & 0 & 0 & 0 & 3783 & 160747 \\
\hline & & Nonfinancial corporations & 6 & 0 & 0 & 0 & 0 & 0 & 0 & 0 & 103 & 17331 \\
\hline & & Financial corporations & 7 & 0 & 0 & 0 & 0 & 0 & 0 & 0 & 79 & 12082 \\
\hline & & Government & 8 & 0 & 0 & 0 & 0 & 0 & 0 & 0 & 615 & 58407 \\
\hline & & $\begin{array}{l}\text { NonProfitInstitutionsServing } \\
\text { Households(NPISH) }\end{array}$ & 9 & 0 & 0 & 0 & 0 & 0 & 0 & 0 & 1 & 3363 \\
\hline & & \multicolumn{2}{|l|}{ Total } & 0 & 0 & 0 & 0 & 0 & 0 & 0 & 4581 & 251931 \\
\hline & \multirow{6}{*}{ 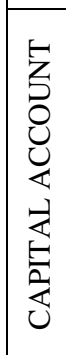 } & Households & 10 & 0 & 0 & 53 & 139 & 0 & 192 & -9004 & 177 & 5093 \\
\hline & & Nonfinancial corporations & 11 & 0 & 0 & 0 & 795 & 0 & 795 & 11407 & 924 & 22029 \\
\hline & & Financial corporations & 12 & 0 & 0 & 53 & 24 & 0 & 77 & -4157 & 0 & 1202 \\
\hline & & Government & 13 & 3 & 95 & 28 & 0 & 2 & 129 & 17135 & 1118 & 6687 \\
\hline & & $\begin{array}{l}\text { NonProfitInstitutionsServing } \\
\text { Households(NPISH) } \\
\end{array}$ & 14 & 0 & 0 & 0 & 344 & 0 & 344 & 840 & 14 & 844 \\
\hline & & Total & & 3 & 95 & 135 & 1301 & 2 & 1536 & 16222 & 2232 & 35856 \\
\hline & \multicolumn{2}{|c|}{ FINANCIAL ACCOUNT } & 15 & 0 & 0 & 0 & 0 & 0 & 0 & 36659 & 37209 & 73868 \\
\hline \multicolumn{3}{|c|}{ REST OF THE WORLD } & 16 & -2179 & 2122 & 3 & 315 & 8 & 268 & 20987 & & 100297 \\
\hline \multicolumn{4}{|c|}{ TOTAL } & 5093 & 22029 & 1202 & 6687 & 844 & 35856 & 73868 & 100297 & \\
\hline
\end{tabular}

Sources: Statistics Portugal (INE); Portuguese Central Bank (Banco de Portugal). 
Approach to the socio-economic activity of countries with a Social Accounting Matrices supported by Socio-Demographic Matrices. An application to Portugal. SSantos

Just as the matrix form of the production accounts may be easily worked on from the supply and use tables, it would also be possible to work on the matrix form of the institutional accounts if some kind of "from whom to whom tables" were made official. This would be a crucial factor for implementing the SAM-based approach, in which SAMs with production and institutional accounts, conveniently capturing the circular flow of income and the underlying network of linkages, would form the basis for macroeconomic models capable of reproducing the multiplier processes implicit in the activity of countries.

\subsection{Aggregates, indicators and balancing items}

As was seen above, practically all the transactions of the national accounts are covered by the SAM, so that macroeconomic aggregates, indicators and balancing items can be identified from it (see the description of the cells or blocks in Table 1, as well as Tables 2 and 3 for the application to Portugal). Gross Domestic Product at market prices $\left(\mathrm{GDP}_{\mathrm{pm}}\right)$, which is usually considered the main macroeconomic aggregate, can be calculated in the three known approaches:

Gross Domestic Product at market prices $\left(\mathrm{GDP}_{\mathrm{pm}}\right)$, which is usually considered the main macroeconomic aggregate, can be calculated in the three known approaches:

- Production approach: $\mathrm{GDP}_{\mathrm{pm}}=\mathrm{P}-\mathrm{IC}+\mathrm{NTP}=\mathrm{t}_{a, \mathrm{p}}-\mathrm{t}_{\mathrm{p}, a}+\left(\mathrm{t}_{\mathrm{dic}, \mathrm{p}}+(\right.$ part of $\left.) \mathrm{t}_{\mathrm{rw}, \mathrm{p}}\right)$;

- Expenditure approach: $\mathrm{GDP}_{\mathrm{pm}}=\mathrm{FC}+\mathrm{GCF}+\mathrm{Ex}-\mathrm{IM}=\mathrm{t}_{\mathrm{p}, \mathrm{dic}}+\mathrm{t}_{\mathrm{p}, \mathrm{dik}}+\mathrm{t}_{\mathrm{p}, \mathrm{rw}}-$ (part of) $\mathrm{t}_{\mathrm{rw}, \mathrm{p}}$;

- Income approach: GDP $\mathrm{pm}_{\mathrm{p}}=\mathrm{GAV}+\mathrm{NTP}+\mathrm{NTA}=\mathrm{t}_{\mathrm{f}, a}+\left(\mathrm{t}_{\mathrm{dic}, \mathrm{p}}+(\right.$ part of $\left.) \mathrm{t}_{\mathrm{rw}, \mathrm{p}}\right)+\left(\mathrm{t}_{\mathrm{dic}, a}+\mathrm{t}_{\mathrm{rw}, a}\right)$.

The Portuguese GDP $\mathrm{pm}_{\text {in }} 2009$ was $168504 * 10^{6}$ euros, which can be calculated from these three approaches as follows:

- $\quad$ Production approach: $\mathrm{GDP}_{\mathrm{pm}}=311365-162661+(19694+106)$;

- $\quad$ Expenditure approach: $\mathrm{GDP}_{\mathrm{pm}}=146934+34051+47236-59717$;

- Income approach: $\mathrm{GDP}_{\mathrm{pm}}=149403+(19694+106)+(522-1222)$.

Domestic Product can be converted into National Product by adding the compensation of factors received from the rest of the world and deducting the compensation of factors and the net indirect taxes (on both products and production) sent to the rest of the world, when these exist. Thus, from the described cells of the basic SAM, GDP ${ }_{\mathrm{pm}}$ can be converted into Gross National Product at market prices $\left(\mathrm{GNP}_{\mathrm{pm}}\right)$ or Gross National Income $\left(\mathrm{GNI}_{\mathrm{pm}}\right)$, as follows: $\mathrm{GDP}_{\mathrm{pm}}+\mathrm{t}_{\mathrm{f}, \mathrm{rw}}-\mathrm{t}_{\mathrm{rw}, \mathrm{f}}-\mathrm{t}_{\mathrm{rw}, a}-$ (part of) $\mathrm{t}_{\mathrm{rw}, \mathrm{p}}$. On the other hand, as the SAM directly provides Gross National Income, this can also be calculated just by adding the net indirect taxes (on both products and production) received by domestic institutions: $t_{\text {dic, } f}+t_{\text {dic }, p}+t_{\text {dic }, a}$. The corresponding amount for Portugal in 2009 is $161639 *$ 
Approach to the socio-economic activity of countries with a Social Accounting Matrices supported by Socio-Demographic Matrices. An application to Portugal. SSantos

$10^{6}$ euros, for which the underlying calculations are as follows: $\mathrm{GNP}_{\mathrm{pm}}=168504+9039-17019-$ $(-1222)-106 ; \mathrm{GNI}_{\mathrm{pm}}=141423+19694+522$.

Disposable Income (Domestic or National) is also very important and can be calculated by adding to $\mathrm{GNI}_{\mathrm{pm}}$ the net current transactions received by domestic institutions: $\mathrm{GNI}_{\mathrm{pm}}+\left((\right.$ received $) \mathrm{t}_{\mathrm{dic}, \mathrm{dic}}+$ $\left.t_{\text {dic,rw }}\right)-\left((\right.$ paid $\left.) t_{d i c, d i c}+t_{r w, d i c}\right)$. In our application to Portugal: $161639+(85711+4581)-(85711+$ $3421)=162800 * 10^{6}$ euros.

In turn, gross aggregates can be converted into net aggregates (and balancing items) by deducting the consumption of fixed capital, which lies outside the basic SAM but is part of the integrated economic accounts.

Gross Saving (S) and Net Lending or Borrowing (NLB) are given directly by the SAM, through $\mathrm{t}_{\text {dik,dic }}$ and $t_{\text {dik,dif }}$, respectively, which in the case of Portugal in 2009 are: 15865 and $16222 * 10^{6}$ euros. As explained in Subsection 4.1 - k), the latter amount represents Net Borrowing.

It is also possible to calculate structural indicators of the functional and institutional distribution of generated income, as well as indicators of the use of disposable income.

In the functional distribution of generated income, the distribution of gross added value - GAV among the factors of production is given by the structure of the submatrix in cell $\mathrm{t}_{\mathrm{f}, a}$ of the basic structure, with its level of detail depending on the disaggregation of the activities (column account) and of the factors of production (row account). Table 4 shows the results for the applications to Portugal.

Table 4. Portuguese functional distribution of the income generated in 2009 (in percentage terms)

\begin{tabular}{|l|r|}
\hline & $\%$ \\
\hline $\begin{array}{l}\text { Factors of Production } \\
\text { (generated income = gross added value or gross domestic product) }\end{array}$ & 57.5 \\
\hline $\begin{array}{l}\text { Labour } \\
\text { (employees) }\end{array}$ & 42.5 \\
\hline $\begin{array}{l}\text { Other } \\
\text { (employers and own-account workers; capital) }\end{array}$ & 100.0 \\
\hline Total
\end{tabular}

Source: Table 3

In the institutional distribution of generated income, the distribution of gross national income - GNI - is given by the structure of the submatrix in cell $t_{\text {dic, } f}$ of the basic structure. In this case, the level of detail will depend on the disaggregation of the factors of production (column account) and of the current account of the domestic institutions (row account). Table 5 shows the results of our application. 
Approach to the socio-economic activity of countries with a Social Accounting Matrices supported by Socio-Demographic Matrices. An application to Portugal. SSantos

Table 5. Portuguese institutional distribution of the income generated in 2009 (in percentage terms)

\begin{tabular}{|c|c|c|c|}
\hline & \multicolumn{3}{|c|}{ Factors of Production } \\
\hline & $\begin{array}{l}\text { Labour } \\
\text { (employees) }\end{array}$ & $\begin{array}{c}\text { Other } \\
\text { (employers and own-account } \\
\text { workers; capital) }\end{array}$ & Total \\
\hline \multicolumn{4}{|c|}{$\begin{array}{l}\text { Institutions } \\
\text { (generated income = gross national income) }\end{array}$} \\
\hline Households & 100.0 & 61.5 & 84.9 \\
\hline Non-financial corporations & & 26.3 & 10.3 \\
\hline Financial corporations & & 10.8 & 4.2 \\
\hline General government & & -0.1 & 0.0 \\
\hline $\begin{array}{l}\text { Non-profit institutions serving } \\
\text { households }\end{array}$ & & 1.5 & 0.6 \\
\hline Total & 100.0 & 100.0 & 100.0 \\
\hline
\end{tabular}

Source: Table 3

As described above for the whole economy, the disposable income of the institutional sectors can be calculated in the same way, and then its distribution and use can also be studied - see Table 6 .

Table 6. Portuguese distribution and use of disposable income among institutions in 2009 (in percentage terms)

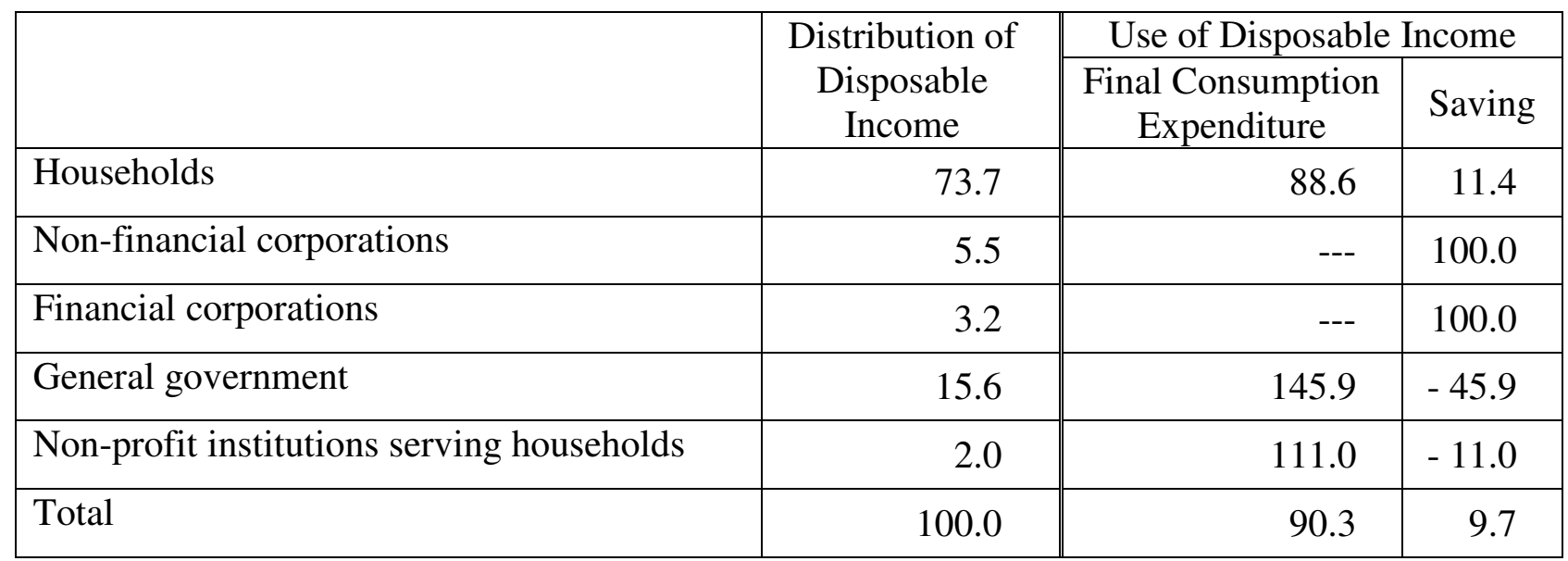

Source: Table 3

The main items in the revenue and expenditure of the institutional sectors and of the rest of the world can be calculated from the respective rows and columns of the SAM. In the case of institutional sectors, the total balancing item is the net lending/borrowing (NLB) of the respective institutional sector, with an opposite mathematical sign to the one registered in the SAM; the current balancing item is the respective gross saving $(\mathrm{S})$; and the capital balancing item is the difference between the first and the second. 
Approach to the socio-economic activity of countries with a Social Accounting Matrices supported by Socio-Demographic Matrices. An application to Portugal. SSantos

\section{The SDM-based approach}

Richard Stone worked largely with SAMs and SDMs as matrix formats of the national and demographic accounts. Besides numerical versions, he identified algebraic versions of those same matrices, which were worked on mainly under the scope of input-output analysis. In keeping with that work, and due to their similarities, as we called in Section 3 the approach based on SAMs the SAM-based approach - the term that is normally adopted - we will call to the approach based on SDMs the SDM-based approach - a term that is not normally adopted, but which will be used here.

Despite the potentialities of Stone's work on SDMs, the SDM-based approach has not been followed by other authors as much as the SAM-based approach. Thus, the study of the SDM-based approach will be based only on Stone's works.

According to this author, the population of a specific country in a specific year "flows in partly along time from last year, through survival, and partly along space from the outside world, through birth and immigration; and flows out, through death and emigration, and partly along time into next year, through survival" (Stone, 1986: 21). With the survivors from the preceding period constituting the opening stock of the population and the survivors into the succeeding period constituting the closing stock, the SDM can thus be considered a stock-flow matrix.

By connecting "the opening and closing stocks of year $\theta$ with flows during year $\theta$ " (Stone, 1982: 292), two types of versions will be identified for the SDM: numerical versions, in which each cell has a specific numerical value; and algebraic versions, in which each cell is filled with algebraic expressions that, together with those of all the other cells, form a SDM-based model.

Numerical versions of SDMs can thus be constructed from demographic statistics or they can be replicated by the running of SDM-based models. The former versions measure the reality under study and will be approached below. The latter versions allow for the construction of scenarios resulting from experiments performed with those models, and can be seen in: Stone, 1966, 1971, 1973, 1975, 1981, 1982, 1985, 1986a.

SDM-based models and the combination of SAM and SDM-based approaches will be part of this author's future research work.

From what was stated in Section 3, just as in any SAM, time and space dimensions can also be identified in any SDM. With an equal number of rows and columns, in each SDM "in any period, the equality of inflows and outflows implies that the difference between the opening and the closing stocks is equal to the net inflow from the outside world" (Stone, 1986: 21). Thus, the SDM connects the opening and the closing stocks of year $\theta$ with the flows during the year $\theta$. 
Approach to the socio-economic activity of countries with a Social Accounting Matrices supported by Socio-Demographic Matrices. An application to Portugal. SSantos

In the standard stock-flow SDM, presented in Table 7, the state at New Year $\theta$ or $\theta+1$ refers to the position on the 1st of January each year.

Table 7. The standard SDM

(Unit: number of individuals)

\begin{tabular}{|l|c|c|c|}
\hline \multicolumn{1}{|c|}{ State at New Year $\theta$} & Outside World & $\begin{array}{c}\text { Our Country: } \\
\text { Opening States }\end{array}$ & $\begin{array}{c}\text { Closing } \\
\text { Stocks }\end{array}$ \\
\hline State at New Year $\theta+1$ & $\alpha$ & $\mathrm{d}$ ' & \\
\hline Outside World & $\mathrm{b}$ & $\mathrm{S}$ & \\
\hline Our Country: Closing States & & $\mathrm{n}$ & \\
\hline
\end{tabular}

Source: Stone $(1981,1982,1986)$

Key:

- $\alpha($ scalar $)=$ individuals who both enter and leave our country during year $\theta$ and so are not recorded in either the opening or the closing stock of that year (babies born in our country during year $\theta$ who die in our country or emigrate before the end of it; immigrants into our country during year $\theta$ who died in our country or emigrate before the end of it).

- $\mathrm{d}$ ' (row vector) $=$ individuals who leave our country during year $\theta$ and so are recorded in the opening stock but are not included in the closing stock (deaths and emigrants of year $\theta$ ).

- $\mathrm{b}($ column vector $)=$ individuals who enter our country during year $\theta$ and so are recorded in the closing stock but are not included in the opening stock (births and immigrants of year $\theta$ ).

- $S($ square matrix $)=$ individuals who survive in our country through year $\theta$ and so are recorded in both the opening and the closing stocks (classified by their opening states in the columns and by their closing states in the rows).

- $\Lambda \mathrm{n}$ (column vector $)=$ closing stock in each state.

- n' (row vector) = opening stock in each state.

The taxonomic framework, within which each study is developed, will depend not only on its purposes, but also on the information available. The whole population must, however, be included. There is no doubt about the complexity of this work and the difficulty of obtaining credible and adequate statistical data.

As seen above, besides the opening and closing stocks, the SDM also quantifies (for each year) the flows of individuals, which are recorded under "our country: (opening or closing) states", defined in accordance with the taxonomic framework adopted. As far as those flows are concerned, adopting the words of Stone, "Each year individuals can enter a state in several ways: by survival in that same state from last year, by moving into it from a different state in the course of the year, by birth or by 
Approach to the socio-economic activity of countries with a Social Accounting Matrices supported by Socio-Demographic Matrices. An application to Portugal. SSantos

immigration; and they may leave it by survival into the year, by moving into another state during the year, by emigration or by death" (Stone, 1986: 22).

Active or passive sequences can be adopted within this framework. In the case of active sequences, different population groups can be identified, including those who are learning - schoolchildren and students; those who are earning - members of the labour force, who participate in the market; and the rest - all the educationally and economically inactive (in the sense that they do not participate in the labour market and do not produce goods and services transacted in the market). Passive sequences cover socio-economic groups, which may include such considerations as income, social class, family size, etc.

The identification of different age groups can be regarded as the necessary step to be taken before working with an active or a passive sequence.

In the following application to Portugal in 2009, in order to better deal with the above-mentioned complexity and to study the so-called economic activity of the population, two levels of disaggregation were identified. At the first level of disaggregation, the population was organised by age groups. At the second level of disaggregation, within each age group, the population was classified as either active or inactive, in accordance with their economic activity, understood as their participation both in the labour market and in the supply side of the goods and services market. With this process of organisation, the difficulty of obtaining data led, in some cases, to the adoption of estimates and assumptions in order to be able to complete the matrices. The hierarchical method, adopted in the previous section (for the construction of the SAM), was adopted. According to this method, each level of disaggregation has all the controlling totals for the next level of that hierarchy. The specification of the sources and the methodologies adopted in the construction of the following SDMs are available in Santos, 2013.

Table 8. SDM of Portugal in 2009 - first level of disaggregation: by age group.

\begin{tabular}{|c|c|c|c|c|c|c|c|}
\hline \multirow{3}{*}{\multicolumn{2}{|c|}{ State at $31 / 12 / 2009$}} & & \multicolumn{5}{|c|}{ (Unit: $10^{3}$ individuals } \\
\hline & & \multirow{2}{*}{$\begin{array}{l}\text { Outside } \\
\text { World }\end{array}$} & \multicolumn{4}{|c|}{ Population in Portugal by age group } & \multirow{2}{*}{$\begin{array}{l}\text { Closing } \\
\text { Stock }\end{array}$} \\
\hline & & & $0-14$ & $15-24$ & $25-64$ & 65 and over & \\
\hline \multicolumn{2}{|c|}{ Outside World } & & 5 & 5 & 25 & 81 & 10638 \\
\hline \multirow{4}{*}{$\begin{array}{l}\text { Population } \\
\text { in Portugal } \\
\text { by age } \\
\text { group }\end{array}$} & $0-14$ & 105 & 1510 & & & & 1615 \\
\hline & $15-24$ & 10 & 110 & 1070 & & & 1190 \\
\hline & $25-64$ & 16 & & 146 & 5790 & & 5952 \\
\hline & 65 and over & 0 & & & 108 & 1772 & 1881 \\
\hline \multicolumn{2}{|c|}{ Opening Stock } & 10623 & 1625 & 1221 & 5924 & 1853 & \\
\hline
\end{tabular}

Source: Statistics Portugal (INE). 
Approach to the socio-economic activity of countries with a Social Accounting Matrices supported by Socio-Demographic Matrices. An application to Portugal. SSantos

In the first age group of the population in Portugal in 2009, represented in Table 8 - column and row $0-14$, we can see the stocks and the flows of children aged 0 to 14 , measured in thousands of individuals. Thus, reading by columns, the opening stock of children was 1,625; of these, 4 died or emigrated, 1,510 remained in that age group throughout the year and 110 moved to the 15-24 age group. Reading by rows, the closing stock was 1,615, which is composed of 105 children surviving births and immigrants and 1,510 children who have not changed state. A similar reading can be made for each of the other columns and rows.

Table 9. SDM of Portugal in 2009 - second level of disaggregation: by age group and economic activity.

(Unit: $10^{3}$ individuals)

\begin{tabular}{|c|c|c|c|c|c|c|c|c|c|c|c|c|c|c|c|}
\hline & \multirow{5}{*}{\begin{tabular}{|c} 
Outside \\
World
\end{tabular}} & \multirow{2}{*}{\multicolumn{10}{|c|}{ Population by age group and economic activity }} & \multirow{4}{*}{$\begin{array}{l}\text { Closing } \\
\text { Stock }\end{array}$} \\
\hline & & & & & & & & & & & & & & & \\
\hline & & & & & \multicolumn{4}{|c|}{$15-24$} & \multicolumn{3}{|c|}{$25-64$} & \multicolumn{3}{|c|}{65 and over } & \\
\hline & & & & & \multirow{2}{*}{$\begin{array}{c}0-14 \\
2\end{array}$} & Active & Inactive & Totol & Active & \multirow{2}{*}{$\begin{array}{c}\text { Inactive } \\
6\end{array}$} & \multirow{2}{*}{ Total } & Active & Inactive & \multirow{2}{*}{ Total } & \\
\hline & & & & & & 3 & 4 & & 5 & & & 7 & 8 & & 9 \\
\hline \multicolumn{3}{|c|}{ Outside World } & 1 & & 5 & 5 & & 5 & 22 & 3 & 25 & 42 & 39 & 81 & 10638 \\
\hline \multirow{10}{*}{ 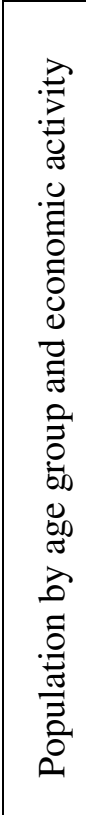 } & & $0-14$ & 2 & 105 & 1510 & & & & & & & & & & 1615 \\
\hline & \multirow{3}{*}{$\begin{array}{l}\stackrel{⿱}{\sim} \\
\stackrel{2}{2}\end{array}$} & Active & 3 & 10 & & 456 & & & & & & & & & 466 \\
\hline & & Inactive & 4 & & 110 & & 614 & & & & & & & & 724 \\
\hline & & Total & & 10 & 110 & & & 1070 & & & & & & & 1190 \\
\hline & \multirow{3}{*}{ 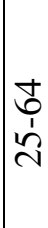 } & Active & 5 & 16 & & 47 & & & 4734 & & & & & & 4797 \\
\hline & & Inactive & 6 & & & & 100 & & & 1056 & & & & & 1156 \\
\hline & & \multicolumn{2}{|l|}{ Total } & 16 & & & & 146 & & & 5790 & & & & 5952 \\
\hline & \multirow{3}{*}{$\begin{array}{l}\dot{\vec{D}} \\
\overrightarrow{0} \\
\vec{z} \\
\tilde{\bar{\sigma}} \\
\tilde{0}\end{array}$} & Active & 7 & 0 & & & & & 35 & & & 284 & & & 320 \\
\hline & & Inactive & 8 & & & & & & & 73 & & & 1488 & & 1561 \\
\hline & & Total & & 0 & & & & & & & 108 & & & 1772 & 1881 \\
\hline \multicolumn{3}{|c|}{ Opening Stock } & 9 & 10623 & 1625 & 508 & 714 & 1221 & 4791 & 1133 & 5924 & 326 & 1527 & 1853 & \\
\hline
\end{tabular}

Source: Statistics Portugal (INE).

The next level of disaggregation will look at the economic activity (as described above) of the population in Portugal in 2009, within each age group and as represented in Table 9. As was seen above, the economically active population amounts to those people that participate in the labour market and/or produce goods and services transacted in the market. Reading the column of the active 
Approach to the socio-economic activity of countries with a Social Accounting Matrices supported by Socio-Demographic Matrices. An application to Portugal. SSantos

15-24 age group, we can see that the opening stock of the active population aged 15 to 24, measured in thousands of individuals, was 508; of these, 5 died or emigrated, 456 remained in the same situation throughout the year and 47 moved to the active 25-64 age group. Reading the row for the same age group, the closing stock was 466, which is composed of 10 immigrants, and 456 who have not changed state. As was stated for the previous level of disaggregation, a similar reading can be made for each of the other columns and rows.

The above-described work with population movements within a country, during a specific period captured by a SDM, can complement and improve the information that has been captured by a SAM regarding the production, consumption and income of the institutional sector of households - one of the five institutional sectors identified by the current System of National Accounts (2008 SNA), the others being: financial and non-financial corporations, government and non-profit institutions serving households.

\section{Examples of studies that can be addressed using a SAM, with the support of a SDM}

\subsection{The socioeconomics of ageing}

Any study of the socioeconomics of ageing conducted in a specific space, namely, a country, should involve the consideration of its population and the corresponding age groups, together with the economic activity of those groups, which should involve the consideration of the origin and the destiny of the corresponding income. In keeping with what was said in the previous section, when all of the population of a country is worked upon within a SDM framework, its movements (expressed in numbers of human beings) can be represented in the form of a stock-flow matrix, which offers many possibilities for disaggregation, especially by age groups. In turn, the flows (expressed in currency units) representing the households' production, consumption and income can be worked upon within a SAM framework.

From what has just been said, SAMs and SDMs, and their underlying approaches, allow for the study of a wide range of different aspects involved in the socioeconomics of ageing (and many other areas), which can be identified in accordance with the purposes of each specific study. Let's suppose that, in studying possible social policy measures, we wish to identify some macroeconomic effects of changes in either the incomes or the expenditures of those whose retirement pensions are their main source of income.

Given such a purpose, our attention necessarily has to be focused, on the one hand, on those who are aged 65 and over, and who are recipients of pensions, i.e. retired and (supposedly) inactive individuals. On the other hand, we should also focus on the corresponding flows of income that are 
Approach to the socio-economic activity of countries with a Social Accounting Matrices supported by Socio-Demographic Matrices. An application to Portugal. SSantos

received and then spent by that group. The following exposition, illustrated by the example of an application to Portugal, will show a simple possible way of using the tools above presented in a study with that particular purpose.

In Table 9, we have a SDM of Portugal in 2009, with a disaggregation that is appropriate for the identification of the above-mentioned group of interest to us here. Thus, in column 8 and row 8 , we have the population aged 65 and over that is considered as inactive described in terms of their participation both in the labour market and in the supply side of the goods and services market. From the reading of this column, we can see that the opening stock of the inactive population aged 65 and over, measured in thousands of individuals, was 1,527 (14.4\% of the total); of these, 39 either died or emigrated and 1,488 remained in the same situation throughout the year. Reading along the row for the same group we can see that the closing stock was 1,561 (14.7\% of the total), which is composed of 73 individuals who moved from the inactive 25-64 age group and 1,488 who did not change their status.

In Table 10, we have a SAM of Portugal in 2009 with a disaggregation that is appropriate for identifying the incomes and expenditures of the same group of interest to us here.

Thus, in row 5 and column 5 we have, respectively, the receipts (or incomes) and the expenditures of the current account of the group of households classified as recipients of pensions regarding their main source of income. Since the row and column totals are equal, they represent the aggregate income of that group, amounting to 25,578 million euros, and the corresponding totals of receipts and expenditures. This amount represents $10.2 \%$ of the total aggregate income. Reading along the row, we can see that this income derived from the compensation of labour and capital - 3,275 million euros $(12.8 \%)$ - while the remaining part came from current transfers within households, from the rest of the world and from the other institutional sectors - 22,302 million euros (87.2\%). In this last figure, the part originating from government, i.e. pensions, represents $73.6 \%$. Reading down the column, we can see that this income was mainly spent on final consumption - 18,778 million euros (73.4\%), transferred in the form of current transfers within households, to the government (namely in the form of current taxes on income, wealth, etc), to the rest of the world and to other institutional sectors 4,515 million euros $(17.7 \%)$. In the reading of the column, we can also see that the part of the aggregate income that was not spent on final consumption or transferred was saved, and amounts to 2,284 million euros $(8.9 \%)$.

This SAM represents all the nominal flows (measured by the national accounts) that occurred in Portugal in 2009. Therefore, from this and as was seen in Section 4.3, we can calculate aggregates, indicators and balancing items, representative of the macroeconomic level of the activity of the 
Approach to the socio-economic activity of countries with a Social Accounting Matrices supported by Socio-Demographic Matrices. An application to Portugal. SSantos

Portuguese economy in that year. That is the case with what is normally considered to be the main macroeconomic aggregate, Gross Domestic Product at market prices ( $\left.\mathrm{GDP}_{\mathrm{pm}}\right)$, amounting to 168,504 million euros. Since our SAM does not identify the institutional sectors in the production accounts, the part corresponding to our group cannot be identified in that amount, although such a calculation is possible in the case of both Gross National Income and Disposable Income. Therefore, in the case of total Gross National Income, with an amount of 161,639 million euros, the share of recipients of pensions was $2.03 \%$, while in the case of total Disposable Income, with an amount of 162,800 million euros, the share of recipients of pensions was $12.94 \%$. 
Approach to the socio-economic activity of countries with a Social Accounting Matrices supported by Socio-Demographic Matrices. An application to Portugal. SSantos

Table 10. SAM of Portugal in $2009^{4}$, with disaggregated factors of production, the (domestic) institutions' current and capital accounts and the households' current account by main source of income (recipients of pensions and others).

(Unit: $10^{6}$ euros)

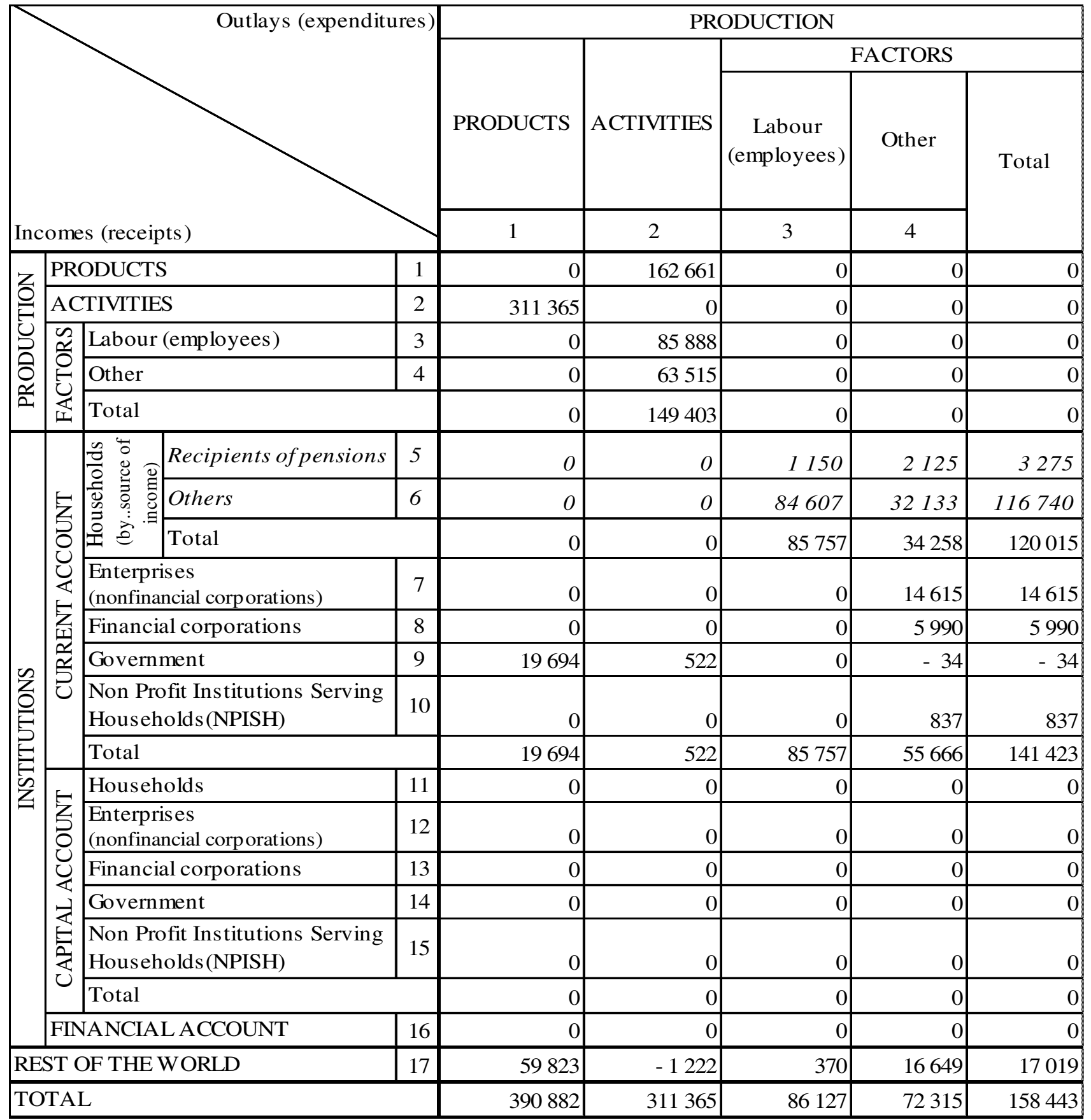

Sources: Statistics Portugal (INE); Portuguese Central Bank (Banco de Portugal).

\footnotetext{
${ }^{4}$ This table is Table 3 showing the households' current account disaggregated by main source of income - rows 5 and 6 and their respective columns, represented in italic font. This disaggregation is an estimate, adopting the same structure of the same account in the SAM worked upon in Santos (2009).
} 
Approach to the socio-economic activity of countries with a Social Accounting Matrices supported by Socio-Demographic Matrices. An application to Portugal. SSantos

Table 10 (continued). SAM of Portugal in 2009, with disaggregated factors of production, the (domestic) institutions' current and capital accounts and the households' current account by main source of income (recipients of pensions and others).

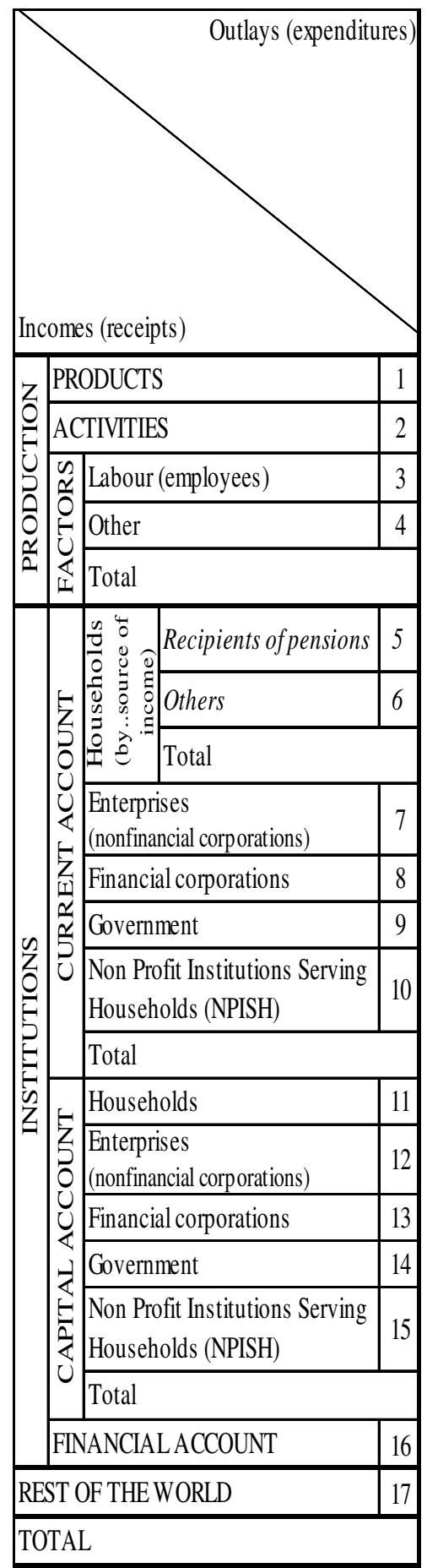

\begin{tabular}{|c|c|c|c|c|c|c|c|}
\hline \multicolumn{8}{|c|}{ INSTITUTIONS } \\
\hline \multicolumn{8}{|c|}{ CURRENT ACCOUNT } \\
\hline (by main & $\begin{array}{l}\text { useholds } \\
\text { ource of in }\end{array}$ & & Enterprises & & & $\begin{array}{l}\text { Non Profit } \\
\text { Institutions }\end{array}$ & \multirow{3}{*}{ Total } \\
\hline $\begin{array}{l}\text { Reciplents } \\
\text { ofpensions }\end{array}$ & Others & \multirow[t]{2}{*}{ Total } & corporations) & corporations & & $\begin{array}{c}\text { Households } \\
\text { (NPISH) }\end{array}$ & \\
\hline 5 & 6 & & 7 & 8 & 9 & 10 & \\
\hline 18778 & 87428 & 106206 & 0 & 0 & 37160 & 3568 & 146934 \\
\hline 0 & 0 & 0 & 0 & 0 & 0 & 0 & 0 \\
\hline 0 & 0 & 0 & 0 & 0 & 0 & 0 & U \\
\hline 0 & 0 & 0 & 0 & 0 & 0 & 0 & S \\
\hline 0 & 0 & 0 & 0 & 0 & 0 & 0 & 0 \\
\hline 11 & 95 & 106 & 1195 & 1982 & 18820 & 63 & 22165 \\
\hline 56 & 639 & 695 & 635 & 3244 & 10178 & 33 & 14784 \\
\hline 67 & 734 & 801 & 1830 & 5226 & 28998 & 95 & 36949 \\
\hline 1486 & 343 & 1830 & 0 & 613 & 171 & 0 & 2613 \\
\hline 443 & 4846 & 5289 & 519 & 131 & 42 & 32 & 6013 \\
\hline 2303 & 28922 & 31224 & 5684 & 671 & 8 & 22 & 37610 \\
\hline 21 & 303 & 324 & 154 & 50 & 1997 & 0 & 2525 \\
\hline 4320 & 35148 & 39468 & 8187 & 6690 & 31215 & 150 & 85711 \\
\hline 2284 & 11444 & 13728 & 0 & 0 & 0 & 0 & 13728 \\
\hline 0 & 0 & 0 & 8903 & 0 & 0 & 0 & 8903 \\
\hline 0 & 0 & 0 & 0 & 5283 & 0 & 0 & 5283 \\
\hline 0 & 0 & 0 & 0 & 0 & -11695 & 0 & -11695 \\
\hline 0 & 0 & 0 & 0 & 0 & 0 & -354 & -354 \\
\hline 2284 & 11444 & 13728 & 8903 & 5283 & -11695 & -354 & 15865 \\
\hline 0 & 0 & 0 & 0 & 0 & 0 & 0 & 0 \\
\hline 195 & 1149 & 1345 & 240 & 110 & 1726 & 0 & 3421 \\
\hline 25578 & 135169 & 160747 & 17331 & 12082 & 58407 & 3363 & 251931 \\
\hline
\end{tabular}

Sources: Statistics Portugal (INE); Portuguese Central Bank (Banco de Portugal). 
Approach to the socio-economic activity of countries with a Social Accounting Matrices supported by Socio-Demographic Matrices. An application to Portugal. SSantos

Table 10 (continued). SAM of Portugal in 2009, with disaggregated factors of production, the (domestic) institutions' current and capital accounts and the households' current account by main source of income (recipients of pensions and others).

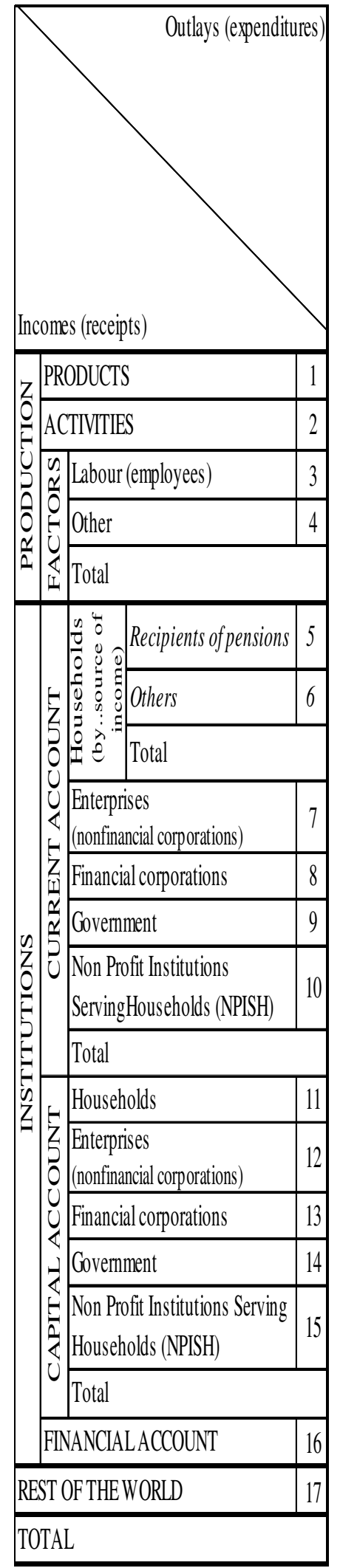

\begin{tabular}{|c|c|c|c|c|c|c|c|c|}
\hline \multicolumn{7}{|c|}{ INSTITUTIONS } & \multirow[b]{3}{*}{$\begin{array}{c}\text { REST OF } \\
\text { THE } \\
\text { WORLD }\end{array}$} & \multirow{4}{*}{ TOTAL } \\
\hline \multicolumn{6}{|c|}{ CAPITALACCOUNT } & \multirow[b]{2}{*}{$\begin{array}{l}\text { FINANCIAL } \\
\text { ACCOUNT }\end{array}$} & & \\
\hline Households & $\begin{array}{c}\text { Enterprises } \\
\text { (nonfinancial } \\
\text { corporations) }\end{array}$ & $\begin{array}{c}\text { Financial } \\
\text { corporations }\end{array}$ & Government & \begin{tabular}{|c|} 
Non Profit \\
Institutions \\
Serving \\
Households \\
(NPISH) \\
\end{tabular} & Total & & & \\
\hline 11 & 12 & 13 & 14 & 15 & & 16 & 17 & \\
\hline 7269 & 19812 & 1064 & 5071 & 834 & 34051 & 0 & 47236 & 39088 \\
\hline 0 & 0 & 0 & 0 & 0 & 0 & 0 & 0 & 311365 \\
\hline 0 & 0 & 0 & 0 & 0 & 0 & 0 & 239 & 86127 \\
\hline 0 & 0 & 0 & 0 & 0 & 0 & 0 & 8800 & 7231 \\
\hline 0 & 0 & 0 & 0 & 0 & 0 & 0 & 9039 & 158 \\
\hline 0 & 0 & 0 & 0 & 0 & 0 & 0 & 138 & 25578 \\
\hline 0 & 0 & 0 & 0 & 0 & 0 & 0 & 3645 & 135169 \\
\hline 0 & 0 & 0 & 0 & 0 & 0 & 0 & 3783 & 16074 \\
\hline 0 & 0 & 0 & 0 & 0 & 0 & 0 & 103 & 17 \\
\hline 0 & 0 & 0 & 0 & 0 & 0 & 0 & 79 & 12082 \\
\hline 0 & 0 & 0 & 0 & 0 & 0 & 0 & 615 & 5840 \\
\hline 0 & 0 & 0 & 0 & 0 & 0 & 0 & & 33 \\
\hline 0 & 0 & 0 & 0 & 0 & 0 & 0 & 4581 & 251 \\
\hline 0 & 0 & 53 & 139 & 0 & 192 & -9004 & 177 & 50 \\
\hline 0 & 0 & 0 & 795 & 0 & 795 & 11407 & 924 & 22029 \\
\hline 0 & 0 & 53 & 24 & 0 & 77 & -4157 & 0 & 120 \\
\hline 3 & 95 & 28 & 0 & 2 & 129 & 17135 & 1118 & 668 \\
\hline 0 & 0 & 0 & 344 & 0 & 344 & 840 & 14 & 84 \\
\hline 3 & 95 & 135 & 1301 & 2 & 1536 & 16222 & 2232 & 35856 \\
\hline 0 & 0 & 0 & 0 & 0 & 0 & 36659 & 37209 & 73868 \\
\hline-2179 & 2122 & 3 & 315 & 8 & 268 & 20987 & $X$ & $10029^{\circ}$ \\
\hline 5093 & 22029 & 1202 & 6687 & 844 & 35856 & 73868 & 100297 & $X$ \\
\hline
\end{tabular}

Sources: Statistics Portugal (INE); Portuguese Central Bank (Banco de Portugal). 
Approach to the socio-economic activity of countries with a Social Accounting Matrices supported by Socio-Demographic Matrices. An application to Portugal. SSantos

In line with the above-mentioned purpose, for a better study of changes in either the incomes or the expenditures of those whose retirement pensions are their main source of income, two scenarios will be sketched out: scenario A, involving a change in incomes; and scenario B, involving a change in expenditures. The numerical SAM and SDM presented above will enable identification of those changes. Algebraic SAMs, representing accounting multipliers (as described in Section 2.2.1 of Santos, 2012) will enable us to quantify the macroeconomic effects of those changes, which will be summarised in the form of the changes occurring in the three above-mentioned macroeconomic aggregates $-\mathrm{GDP}_{\mathrm{pm}}$, Gross National Income and Disposable Income.

Taking advantage of the availability of the SDM, those scenarios will involve the increase noted between the opening and the closing stocks of the group of inactive individuals aged 65 and over. This increase could be calculated from cells $(9,8$ and 8,9) of Table 9 and was $2.2 \%$.

If we assume that the per capita receipts and expenditures (considering the closing stock of our group) that can be calculated from the SAM and the SDM are the same, and that all the rest remains constant, the effects of that increase on the main items of income and expenditure of our particular group of interest will constitute scenarios $\mathrm{A}$ and $\mathrm{B}$, respectively.

As was seen above, the main item of income in our group of individuals is pensions, which amount to current transfers from the government. Scenario A will therefore show the effects of an increase in current transfers from the government, resulting from an increase of $2.2 \%$ in the group of inactive individuals aged 65 and over, with the received per capita amount remaining the same. Considering the value of cell $(5,9)$ of Table 10, this would represent an increase of approximately 420 million euros in the amount of current transfers from the government to the recipients of pensions. Since the current and capital accounts of the government, as well as the financial and the rest of the world accounts, are considered exogenous, from the running of the accounting multipliers, calculated from the SAM for Portugal in 2009, it can be seen that the effect of such a change on the endogenous part of the SAM showed an increase of $0.31 \%$ in $\mathrm{GDP}_{\mathrm{pm}}$. At the level of Gross National Income, this effect represents an increase of $0.30 \%$ in total income and a rise of $0.29 \%$ in the share of the recipients of pensions. In turn, the effect on Disposable Income also took the form of an increase of $0.29 \%$ in total income and $2.67 \%$ in the share of the recipients of pensions.

In turn, scenario B will represent the effect of an increase in final consumption resulting from an increase of $2.2 \%$ in the group of inactive individuals aged 65 and over, with the consumed per capita amount remaining the same. Considering the value of cell $(1,5)$ of Table 10, this would represent an increase of approximately 378 million euros in the final consumption of the recipients of pensions. 
Approach to the socio-economic activity of countries with a Social Accounting Matrices supported by Socio-Demographic Matrices. An application to Portugal. SSantos

Since the current and capital accounts of the two groups of households, as well as the financial and the rest of the world accounts, are considered to be exogenous, from the running of the accounting multipliers, calculated from the SAM for Portugal in 2009, it can be seen that the effect of such a change on the endogenous part of the SAM now represents an increase of $0.18 \%$ in $\mathrm{GDP}_{\mathrm{pm}}$. The effects on Gross National Income (both in total and in the part relating to the share of recipients of pensions) and on total Disposable Income was an increase of $0.17 \%$, whereas, in the part of Disposable Income that relates to the recipients of pensions, there was an increase of $0.11 \%$.

\subsection{The informal aspects of the activity of countries}

Chapter 25 of the 2008 SNA (System of National Accounts) identifies in the activity of countries a part "that reflects the effort of people without formal jobs to engage in some form of monetary economic activity" (ISWGNA, 2009: 471), in which the household unincorporated enterprises, operating within the production boundary of the $\mathrm{SNA}^{5}$, sell or barter on the market most or all of their output; in other words, they have market output. Because they operate on a small scale, at a low level of organisation, with little or no division between factors of production, the income that is generated by their activity is the so-called mixed income. Thus, as is mentioned in Chapters 7 and 24 of the 2008 SNA, the mixed income is the compensation of the owner(s) of an unincorporated enterprise or members of the same household that may contribute with unpaid labour inputs of a similar kind to those that could be provided by paid employees. Since the household unincorporated enterprises may operate with or without paid employees, the distinction can be established respectively between employers' mixed income and own-account workers' mixed income. Employers and own-account workers are often named self-employed.

Within the framework of the proposed SAM, this compensation of employers and own-account workers can be added to the compensation of employees, thus completing total compensation of labour in the gross added value of the activity of countries, together with the corresponding contribution to the functional distribution of the generated income. In turn, when we think of the institutional distribution of the generated income, the disaggregation of the households may follow what which is defined in Chapter 4-G of the 2008 SNA, in other words in accordance with their main source of income (ISWGNA, 2009: 82-84). The following groups could be studied: employees; employers and own-account workers; recipients of property and transfer income. However, after it is generated, this income follows a path during which it is distributed among institutions and

\footnotetext{
${ }^{5}$ As defined in Chapter 6 of the 2008 SNA (ISWGNA, 2009: 98-101).
} 
Approach to the socio-economic activity of countries with a Social Accounting Matrices supported by Socio-Demographic Matrices. An application to Portugal. SSantos

accumulated by institutions, and this factor should not be neglected, otherwise a part of the network of linkages underlying the activity of countries would be missed.

In this respect, we should bear in mind the two general principles recommended by Pyatt and Round regarding the taxonomy to be adopted in the SAMs' design: "the classifications adopted for factors, for goods and non-factor services, and also for institutions need to be developed jointly" (the activities would certainly be included here, if they had been included in the SAM used in the article ${ }^{6}$ ); and the "classification system should be designed in such a way that any underlying duality is apparent" (Pyatt and Round, 2012: 267). Respecting these principles avoids overlooking important parts (which may even be crucial) of the network of linkages, which we have been referring to.

In Table 12, we have a SAM for Portugal in 2009 with a disaggregation that is appropriate for the identification of the informal aspects of the activity of countries, involving both production, and institutional accounts, and their corresponding blocks, with special attention being paid to the factors account in the former case and to the (current, capital, and eventually the financial) account of households, in the latter case.

If we assume that the above-mentioned informal part of the activity of countries is observed by the corresponding national accounts, its study will require the disaggregation of those accounts, and so the consistency with the whole system will automatically be guaranteed. Otherwise, those accounts will need to be extended further, and the whole system will need to be adjusted.

Whether in the case of disaggregation or in the case of extension, in the factors accounts, both formal labour (employees) and informal labour (employers and own-account workers) should be identified, with adjustments being made for activities and for products, if these are considered important. In turn, in the institutional accounts, formal and informal households should also be identified. Formal households will be those that, according to their main source of income, are employees or recipients of property and transfer income. The informal households will be those that, according to their main source of income, are employers or own-account workers.

In turn, in the SDM structure that we are proposing, those who participate in the labour market and in the supply side of the goods and services market represent the active population, which can be employed or unemployed. Within the employed category, we will identify employees as being formal, and employers and own-account workers, as being informal. Thus, in a study of the informal aspects of the activity in a specific space, namely, a country, the consideration of its population and the above

\footnotetext{
${ }^{6}$ The inclusion of separate accounts for production activities was not considered important in the context of the article (Pyatt and Round, 2012: 252).
} 
Approach to the socio-economic activity of countries with a Social Accounting Matrices supported by Socio-Demographic Matrices. An application to Portugal. SSantos

described groups should involve the economic activity of those groups and also the corresponding origin and the destination of their income.

As mentioned above, SAMs and SDMs, and their underlying approaches, allow for the study of a wide range of different aspects involved in the informal aspects of the countries' activity (and many other areas), which can be identified in accordance with the purposes of each specific study. Let's suppose that, in studying a possible increment of the informal aspects of the activity of countries, we wish to identify some macroeconomic effects of increases in the compensation of the informal labour on one hand, and, on the other hand, in either the incomes or the expenditures of the informal households. That possible increment can be seen both as an effort to correct a possible undervaluation of the activity of the household unincorporated enterprises by the national accounts, and also as an alternative to absorb a part of existing unemployment.

Given such a purpose, our attention necessarily has to be focused, on one hand, on those who are active and informally employed and, on the other hand, on the corresponding flows of income that are received and then spent by the group whose main source of income comes from the corresponding activity - the informal households. The following exposition, illustrated by the example of an application to Portugal, will show a simple possible way of using the tools presented above in a study with that particular purpose.

Table 11 shows a SDM of Portugal in 2009- the third level of disaggregation, following the sequence of the previous section, with a disaggregation which allows for the identification of those who are informally employed, as described above, in columns and rows 4, 8 and 12, grouped by age levels. Because the numbers of the 15-24 age group, column and row 4, are insignificant, our attention will be focused on the other two groups.

Thus, when reading column 8 it can be seen that the opening stock of the informally employed, aged 25-64, measured in thousands of individuals, was 915 (8.6\% of the total population and $75.7 \%$ of the total informally employed); of these, 3 either died or emigrated, 876 remained in the same situation throughout the year, 6 became unemployed and 30 moved to the informally employed 65 and over age group. Reading along the row (8) for the same group it can be seen that the closing stock was 878, which is composed of (approximately) 1 thousand individuals who moved from the informally employed 15-24 age group and (approximately) 876 who did not change their status.

In the case of the population aged 65 and over that is informally employed, from the reading of column 12, shows that it is represented by 293 thousands of individuals ( $2.8 \%$ of the total population and $24.2 \%$ of the total informally employed); of these, 37 either died or emigrated and 256 remained in the same situation throughout the year. 
Approach to the socio-economic activity of countries with a Social Accounting Matrices supported by Socio-Demographic Matrices. An application to Portugal. SSantos

Table 11. SDM of Portugal in 2009- third level of disaggregation: by age group, economic activity and market participation.

(Unit: $10^{3}$ individuals)

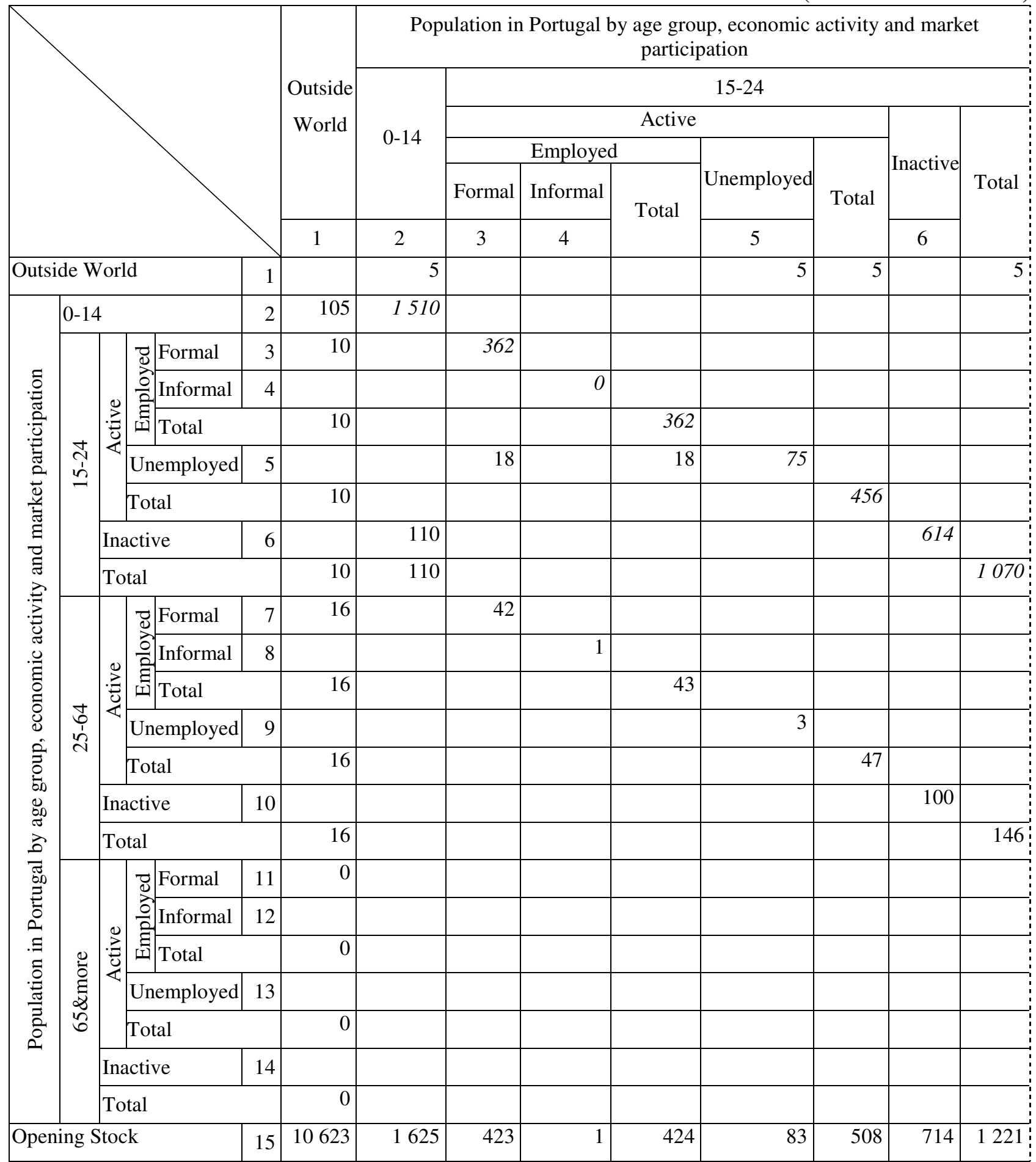

Source: Statistics Portugal (INE)

\footnotetext{
${ }^{7}$ This table is Table 9, showing the active population disaggregated in accordance with its participation in the labour market and in the supply side of the goods and services market, with two further levels of disaggregation, constructed from the same sources of information and adopting an identical methodology, with the required adaptations.
} 
Approach to the socio-economic activity of countries with a Social Accounting Matrices supported by Socio-Demographic Matrices. An application to Portugal. SSantos

Table 11 (continued). SDM of Portugal in 2009- third level of disaggregation: by age group, economic activity and market participation.

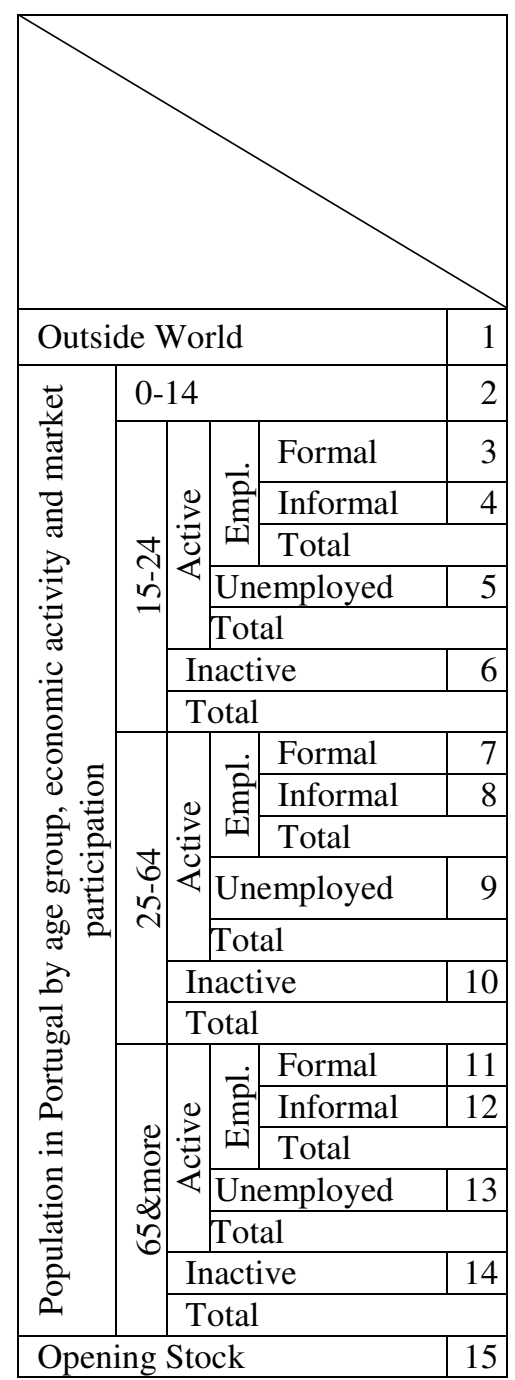

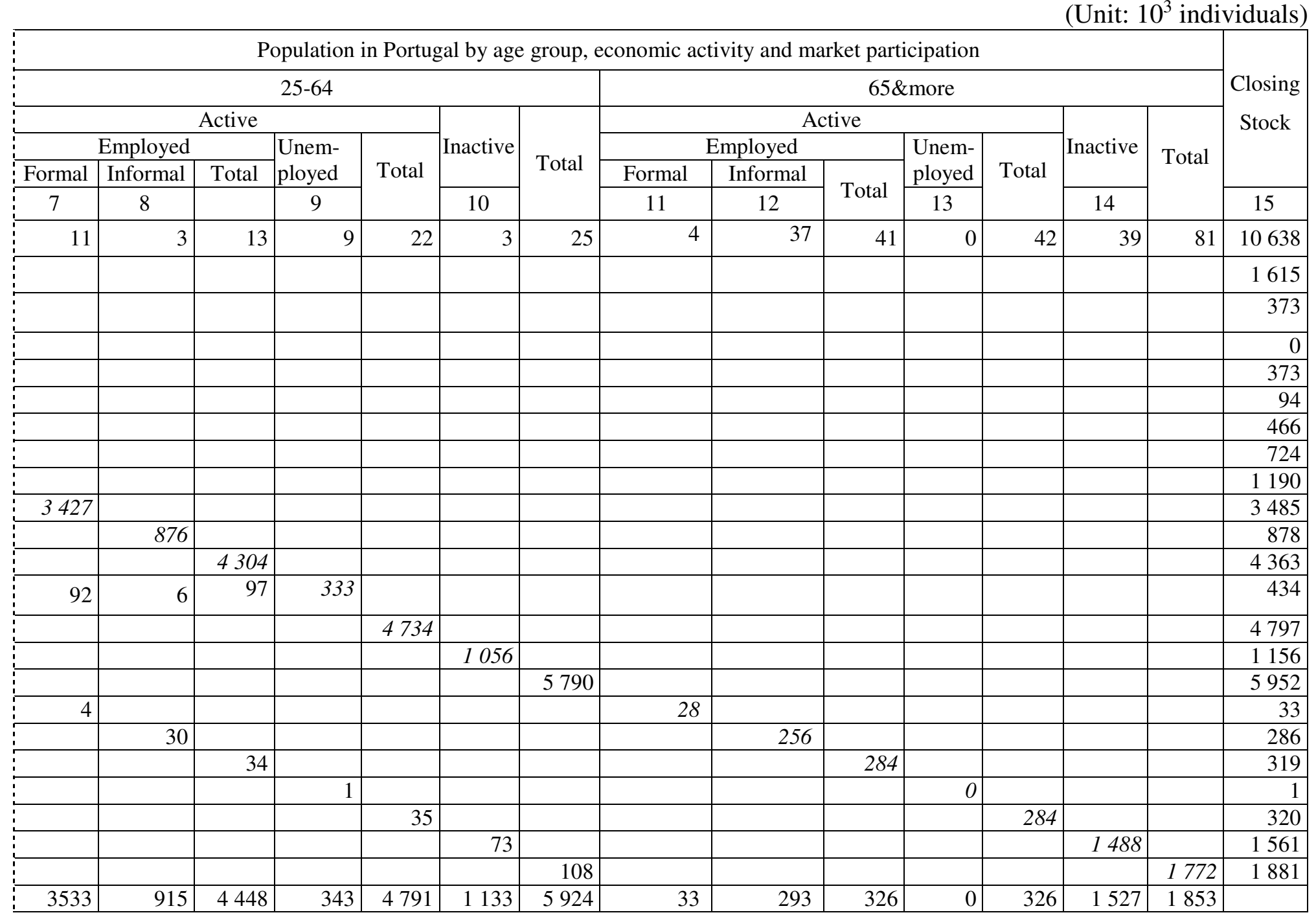

Source: Statistics Portugal (INE). 
In turn, Table 12 shows a SAM of Portugal in 2009, with a disaggregation that allows the identification of the flows of income that are received and spent by informal households, through their current account, as well as, the compensation of informal labour (employers and own-account workers).

Thus, in row and column 4 the aggregate factors income related to informal labour can be seen, i.e. the above referred gross mixed income, which amounts to 17,745 million Euros and represent 11.2\% of total aggregate factors income. From the reading in column it is also possible to see that $81.3 \%$ of the gross mixed income (14,418 million Euros) is received by the informal households, being the remaining $18.7 \%$ being received by the formal households, as characterized above.

In turn, row and column 7 show, respectively, the receipts (or incomes) and the expenditures of the current account of the group of households whose main source of income is the compensation of informal labour ${ }^{8}$. Since the row and column totals are equal, they represent the aggregate income of that group, amounting to 30,601 million Euros, and the corresponding totals of receipts and expenditures. This amount represents $12.1 \%$ of the total aggregate income. Reading along the row, one can see that this income is derived from the compensation of labour and capital - 26,374 million Euros $(86.2 \%)$ - while the remaining part came from current transfers within households, from the rest of the world and from other institutional sectors - 4,227 million Euros (13.8\%). Reading down the column, one can see that this income was mainly spent on final consumption - 15,935 million Euros $(52.1 \%)$, transferred in the form of current transfers: within households, to the government (namely in the form of current taxes on income, wealth, etc), to the rest of the world and to other institutional sectors - 3,643 million Euros $(11.9 \%)$. In reading the column, one can also see that the part of the aggregate income that was not spent on final consumption or transferred, was saved, and this amounts to 11,023 million Euros (36.0\%), which represent a significant proportion, especially when compared with that of the formal households: $2.1 \%$.

\footnotetext{
${ }^{8}$ For a better understanding of the following reading, see Santos (2013) - Section 4.
} 
Approach to the socio-economic activity of countries with a Social Accounting Matrices supported by Socio-Demographic Matrices. An application to Portugal. SSantos

Table $12^{9}$. SAM of Portugal in 2009, with disaggregated factors of production (formal and informal labour), the (domestic) institutions' current and capital accounts and the households' current account by main source of income (formal and informal).

(Unit: $10^{6}$ Euros)

\begin{tabular}{|c|c|c|c|c|c|c|c|c|c|}
\hline \multicolumn{4}{|c|}{ Outlays (expenditures) } & \multicolumn{6}{|c|}{ PRODUCTION } \\
\hline & & & & \multirow{3}{*}{ PRODUCTS } & \multirow{3}{*}{ ACTIVITIES } & \multicolumn{4}{|c|}{ FACTORS } \\
\hline & & & & & & \multicolumn{2}{|c|}{ Labour } & \multirow[b]{2}{*}{ Capital } & \multirow{3}{*}{ Total } \\
\hline & & & & & & Formal & Informal & & \\
\hline \multicolumn{4}{|c|}{ Incomes (receipts) } & 1 & 2 & 3 & 4 & 5 & \\
\hline \multirow{6}{*}{$\begin{array}{l}z \\
\\
0 \\
0 \\
0\end{array}$} & \multicolumn{2}{|c|}{ PRODUCTS } & 1 & 0 & 162661 & 0 & 0 & 0 & 0 \\
\hline & \multicolumn{2}{|c|}{ ACTIVITIES } & 2 & 311365 & 0 & 0 & 0 & 0 & 0 \\
\hline & & \begin{tabular}{|l|l|} 
& Formal \\
\end{tabular} & 3 & 0 & 85888 & 0 & 0 & 0 & 0 \\
\hline & \multirow{3}{*}{$\overbrace{0}^{2}$} & \begin{tabular}{l} 
Labour \\
\cline { 2 - 3 }
\end{tabular} & 4 & 0 & 17745 & 0 & 0 & 0 & 0 \\
\hline & & Capital & 5 & 0 & 45770 & 0 & 0 & 0 & 0 \\
\hline & & \multicolumn{2}{|l|}{ Total } & 0 & 149403 & 0 & 0 & 0 & 0 \\
\hline \multirow{15}{*}{ 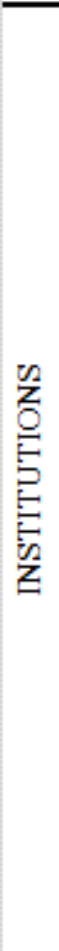 } & \multirow{8}{*}{ 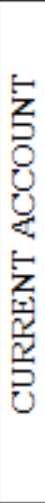 } & \multirow{3}{*}{\multicolumn{2}{|c|}{ 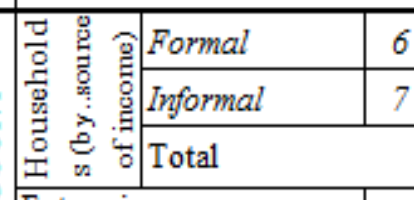 }} & 0 & 0 & 81724 & 3327 & 8591 & 93641 \\
\hline & & & & 0 & 0 & 4033 & 14418 & 7922 & 26374 \\
\hline & & & & 0 & 0 & 85757 & 17745 & 16513 & 120015 \\
\hline & & $\begin{array}{l}\text { Enterprises } \\
\text { (nonfinancial corporations) }\end{array}$ & 8 & 0 & 0 & 0 & 0 & 14615 & 14615 \\
\hline & & Financial corporations & 9 & 0 & 0 & 0 & 0 & 5990 & 5990 \\
\hline & & Government & 10 & 19694 & 522 & 0 & 0 & -34 & -34 \\
\hline & & $\begin{array}{l}\text { NonProfitInstitutionsSer } \\
\text { vingHouseholds(NPISH) }\end{array}$ & 11 & 0 & 0 & 0 & 0 & 837 & 837 \\
\hline & & Total & & 19694 & 522 & 85757 & 17745 & 37921 & 141423 \\
\hline & $E$ & Households & 12 & 0 & 0 & 0 & 0 & 0 & 0 \\
\hline & 8 & $\begin{array}{l}\text { Enterprises } \\
\text { (nonfinancial corporations) }\end{array}$ & 13 & 0 & 0 & 0 & 0 & 0 & 0 \\
\hline & $\Leftrightarrow$ & Financial corporations & 14 & 0 & 0 & 0 & 0 & 0 & 0 \\
\hline & ¿ & Government & 15 & 0 & 0 & 0 & 0 & 0 & 0 \\
\hline & 它 & $\begin{array}{l}\text { NonProfitInstitutionsSer } \\
\text { vingHouseholds(NPISH) }\end{array}$ & 16 & 0 & 0 & 0 & 0 & 0 & 0 \\
\hline & 0 & Total & & 0 & 0 & 0 & 0 & 0 & 0 \\
\hline & FIN & ANCIAL ACCOUNT & 17 & 0 & 0 & 0 & 0 & 0 & 0 \\
\hline RES & $\mathrm{TOF}$ & FTE WORLD & 18 & 59823 & -1222 & 370 & 0 & 16649 & 17019 \\
\hline TO & $\mathrm{AL}$ & & & 390882 & 311365 & 86127 & 17745 & 54571 & 158443 \\
\hline
\end{tabular}

Sources: Statistics Portugal (INE); Portuguese Central Bank (Banco de Portugal).

\footnotetext{
${ }^{9}$ This table is Table 3 of Santos (2013) showing the other factors' account disaggregated by informal labour and capital (rows and columns 4 and 5) and households' current account disaggregated by main source of income (rows and columns 6 and 7), represented in italic font. In this disaggregation the data that could not be taken from the integrated economic accounts, are in italic font and were estimated, adopting the same structure of the same account in the SAM worked upon in Santos (2009).
} 
Approach to the socio-economic activity of countries with a Social Accounting Matrices supported by Socio-Demographic Matrices. An application to Portugal. SSantos

Table 12 (continued). SAM of Portugal in 2009, with disaggregated factors of production (formal and informal labour), the (domestic) institutions' current and capital accounts and the households' current account by main source of income (formal and informal).

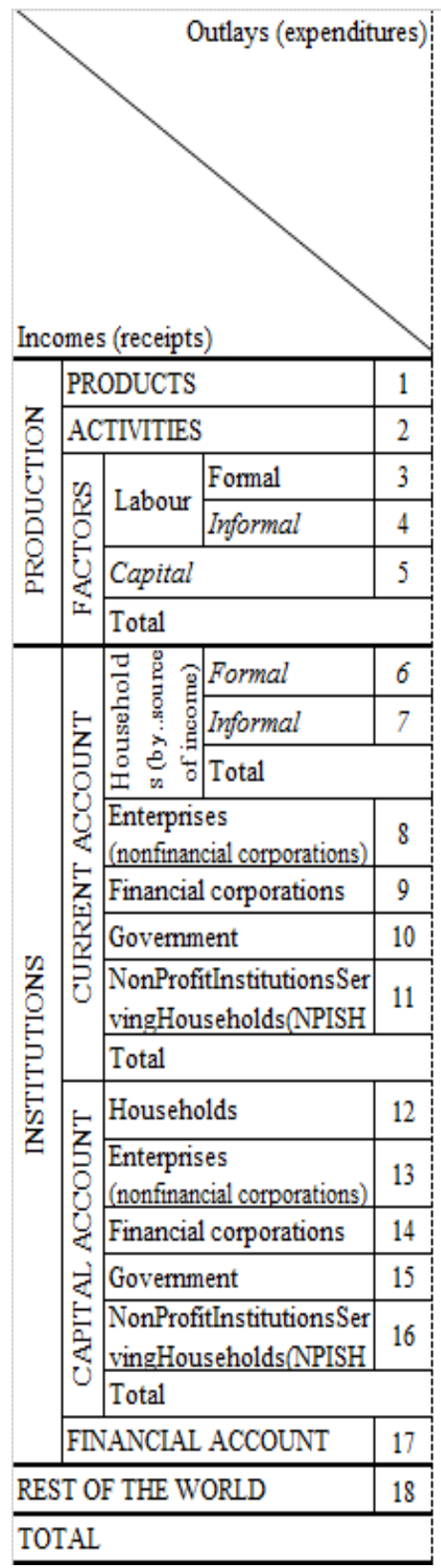

\begin{tabular}{|c|c|c|c|c|c|c|c|}
\hline \multicolumn{8}{|c|}{ INSTITUTIONS } \\
\hline \multicolumn{8}{|c|}{ CURRENT ACCOUNT } \\
\hline \multicolumn{3}{|c|}{ Households (by main source of income) } & \multirow[b]{2}{*}{$\begin{array}{c}\text { Enterprises } \\
\text { (nonfinancial } \\
\text { corporations) }\end{array}$} & \multirow[b]{2}{*}{$\begin{array}{c}\text { Financial } \\
\text { corporations }\end{array}$} & \multirow[b]{2}{*}{ Government } & \multirow[b]{2}{*}{$\begin{array}{c}\text { NonProfitInsti- } \\
\text { tutionsServing } \\
\text { Households } \\
\text { (NPISH) }\end{array}$} & \multirow{3}{*}{ Total } \\
\hline Formal & Informal & \multirow[t]{2}{*}{ Total } & & & & & \\
\hline 6 & 7 & & 8 & 9 & 10 & 11 & \\
\hline 90271 & 15935 & 106206 & 0 & 0 & 37160 & 3568 & 146934 \\
\hline 0 & 0 & 0 & 0 & 0 & 0 & 0 & 0 \\
\hline 0 & 0 & 0 & 0 & 0 & 0 & 0 & 0 \\
\hline 0 & 0 & 0 & 0 & 0 & 0 & 0 & 0 \\
\hline 0 & 0 & 0 & 0 & 0 & 0 & 0 & 0 \\
\hline 0 & 0 & 0 & 0 & 0 & 0 & 0 & 0 \\
\hline 499 & 155 & 655 & 1662 & 4855 & 26330 & 86 & 33588 \\
\hline 112 & 35 & 146 & 168 & 370 & 2668 & 9 & 3361 \\
\hline 611 & 190 & 801 & 1830 & 5226 & 28998 & 95 & 36949 \\
\hline 1663 & 167 & 1830 & 0 & 613 & 171 & 0 & 2613 \\
\hline 4734 & 555 & 5289 & 519 & 131 & 42 & 32 & 6013 \\
\hline 28838 & 2386 & 31224 & 5684 & 671 & 8 & 22 & 37610 \\
\hline 259 & 65 & 324 & 154 & 50 & 1997 & 0 & 2525 \\
\hline 36105 & 3363 & 39468 & 8187 & 6690 & 31215 & 150 & 85711 \\
\hline 2705 & 11023 & 13728 & 0 & 0 & 0 & 0 & 13728 \\
\hline 0 & 0 & 0 & 8903 & 0 & 0 & 0 & 8903 \\
\hline 0 & 0 & 0 & 0 & 5283 & 0 & 0 & 5283 \\
\hline 0 & 0 & 0 & 0 & 0 & -11695 & 0 & -11695 \\
\hline 0 & 0 & 0 & 0 & 0 & 0 & -354 & -354 \\
\hline 2705 & 11023 & 13728 & 8903 & 5283 & -11695 & -354 & 15865 \\
\hline 0 & 0 & 0 & 0 & 0 & 0 & 0 & 0 \\
\hline 1065 & 280 & 1345 & 240 & 110 & 1726 & 0 & 3421 \\
\hline 130146 & 30601 & 160747 & 17331 & 12082 & 58407 & 3363 & 251931 \\
\hline
\end{tabular}

Sources: Statistics Portugal (INE); Portuguese Central Bank (Banco de Portugal). 
Approach to the socio-economic activity of countries with a Social Accounting Matrices supported by Socio-Demographic Matrices. An application to Portugal. SSantos

Table 12 (continued). SAM of Portugal in 2009, with disaggregated factors of production (formal and informal labour), the (domestic) institutions' current and capital accounts and the households' current account by main source of income (formal and informal).

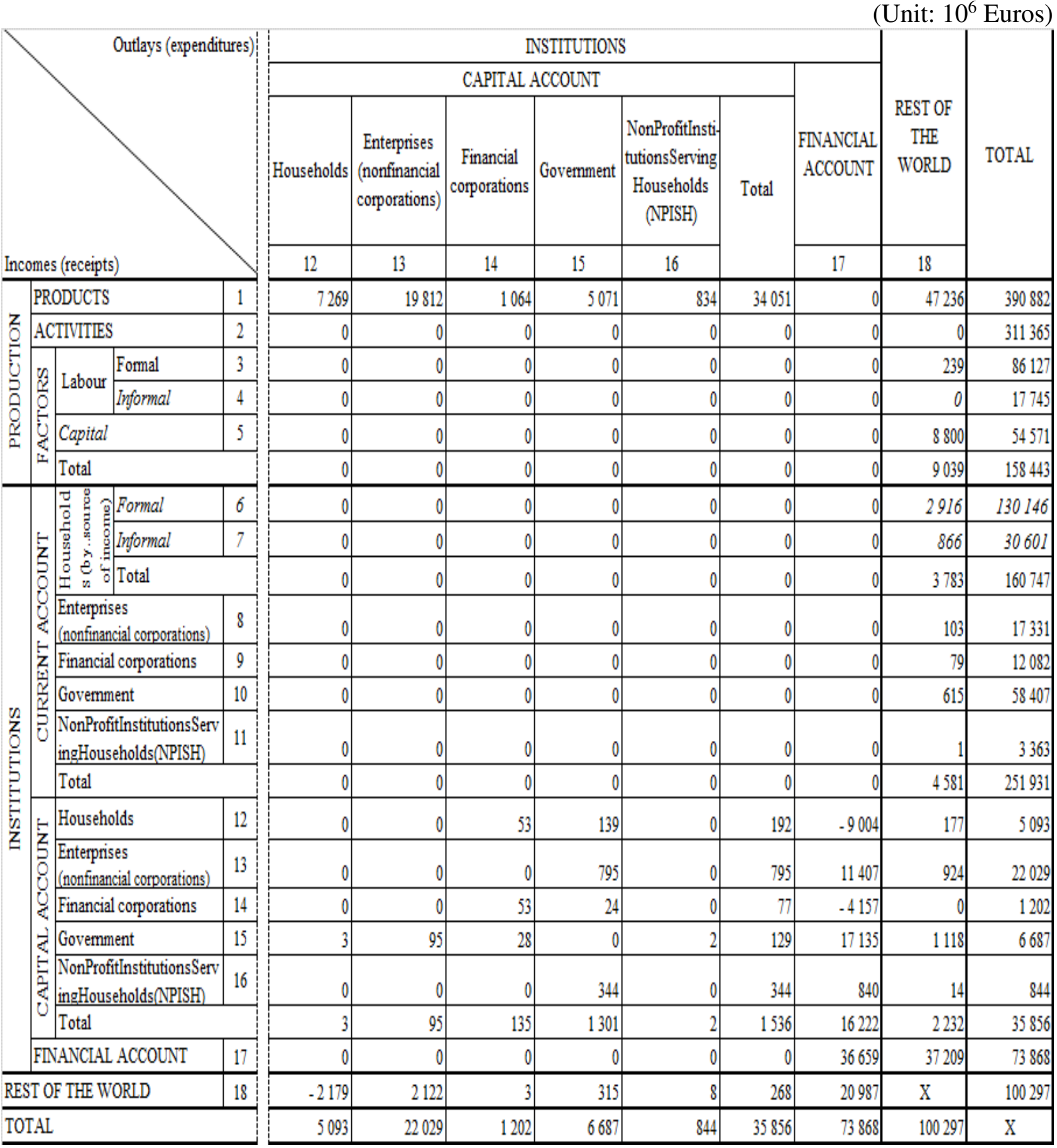

Sources: Statistics Portugal (INE); Portuguese Central Bank (Banco de Portugal).

As mentioned above, this SAM represents all the nominal flows (measured by the national accounts) that occurred in Portugal in 2009, from which one can calculate aggregates, indicators and balancing items, representative of the macroeconomic level of the activity of the Portuguese economy for that year. This is the case with what is normally considered to be the main macroeconomic aggregate - 
Approach to the socio-economic activity of countries with a Social Accounting Matrices supported by Socio-Demographic Matrices. An application to Portugal. SSantos

Gross Domestic Product at market prices $\left(\mathrm{GDP}_{\mathrm{pm}}\right)$, which amounts to 168,504 million Euros. Since our SAM does not identify the institutional sectors in the production accounts, the part corresponding to our group of study cannot be identified in that amount, although such a calculation is possible in the case of both Gross National Income and Disposable Income. Therefore, in the case of total Gross National Income, which has an amount of 161,639 million Euros, the share of informal households was $16.3 \%$, while in the case of total Disposable Income, with an amount of 162,800 million Euros, the share of informal households was $16.6 \%$.

In line with the above-mentioned purpose, for a better study of changes resulting from the increment of the informal aspects of the activity of countries, three scenarios will be presented: scenario C, involving an increase in gross mixed income (the total compensation of the informal labour); scenario $\mathrm{D}$ involving an increase in the part of the gross national income relating to the compensation of informal labour received by informal households; and scenario E, involving an increase in final consumption of informal households. The numerical SAM and SDM presented above will enable the identification of those changes. Algebraic SAMs, representing accounting multipliers (as described in Section 2.2.1 of Santos, 2012) will enable the quantification of the macroeconomic effects of those increases, which will be summarised in the form of the changes occurring in the three abovementioned macroeconomic aggregates: $\mathrm{GDP}_{\mathrm{pm}}$, Gross National Income and Disposable Income, as shown in Table 13.

In scenario C, our attention was focused, on one hand, on cell $(4,2)$ of the SAM, which represents the gross mixed income, or the total compensation of the informal labour, amounting to 17,745 million Euros, and, on the other hand, on the sum of the totals of columns 4, 8 and 12 of the SDM, which represent the opening stock of the informally employed, amounting to 1,209 thousand individuals. An increase of $20 \%$ was then applied to the informally employed, who became 1,451 thousand individuals. Assuming that the gross mixed income per informally employed remained the same, the new total amount in cell $(4,2)$ of the SAM became 21,294 million Euros, which represents an increase of 3,549 million Euros in the total compensation of informal labour, or gross mixed income.

In scenarios D and E, increases of $20 \%$ were applied, respectively, to the part of the gross national income relating to the compensation of informal labour, received by informal households and to the final consumption of the informal households. That represent increases of 2,884 million Euros in SAM's cell $(7,4)$, in the former case, and of 3,187 million Euros in SAM's cell $(1,7)$, in the latter case.

Considering as exogenous the accounts whose outlays are affected by the increases in each scenario, as well as the financial and the rest of the world accounts, from the running of the accounting 
Approach to the socio-economic activity of countries with a Social Accounting Matrices supported by Socio-Demographic Matrices. An application to Portugal. SSantos

multipliers, calculated from the SAM of Portugal in 2009, the effects of such increases on the endogenous part of the SAM are summarized by the changes in the macroeconomic aggregates represented in Table 13.

Table 13. Percentage changes in macroeconomic aggregates in the three scenarios of possible increases in informal aspects of the activity of Portugal in 2009

\begin{tabular}{|l|l|c|c|c|}
\hline \multicolumn{2}{|l|}{} & Scenario C & Scenario D & Scenario E \\
\hline \multicolumn{2}{|l|}{$\begin{array}{r}\text { Gross Domestic Product (GDP) at market prices } \\
\text { - Total }\end{array}$} & 2.23 & 3.64 & 3.10 \\
\hline \multirow{2}{*}{$\begin{array}{l}\text { Gross National Income } \\
\text { (GNI) }\end{array}$} & Total & 2.33 & 4.88 & 2.98 \\
\cline { 2 - 5 } & Informal Households & 10.93 & 12.41 & 2.95 \\
\hline \multirow{2}{*}{\begin{tabular}{l} 
Disposable Income (DI) \\
\cline { 2 - 5 }
\end{tabular}} & Total & 2.27 & 4.76 & 2.90 \\
\cline { 2 - 5 } & Informal Households & 9.55 & 11.11 & 3.22 \\
\hline
\end{tabular}

Source: Own calculations.

Thus, the effects of an increase in gross mixed income (scenario C) were felt mainly at the level of the part of informal households in GNI and in DI. The totals of those aggregates, as well as, that of GDP, felt much lower or very identical effects.

In turn, the effects of an increase in compensation of informal labour received by informal households (scenario D) were felt in an identical form as the previous, but with higher impacts.

The effects of an increase in the final consumption of informal households (scenario E) were felt in a more undifferentiated manner in the selected aggregates, although in terms of totals they are higher than those verified with an increase in gross mixed income.

\section{Summary and concluding remarks}

Social Accounting Matrices (SAM) are tools for working with the socio-economic activity of countries either empirically and theoretically, depending on whether they are presented in a numerical or an algebraic version. This is the so-called SAM-based approach for studying (measuring and modelling) the socio-economic activity of countries.

Assuming that the national accounts are the core of the statistics representing the socio-economic activity of countries, their adoption is recommended, at least as a starting point, for any study that is looking for empirical evidence about that activity. This will enable us to work with, and gain greater knowledge about, the activity that is (supposedly) observed by the national accounts, which in a SAM framework will benefit from the increased analytical content provided by the matrix format and the possibility of capturing and working with networks of linkages not captured and worked on otherwise. 
Approach to the socio-economic activity of countries with a Social Accounting Matrices supported by Socio-Demographic Matrices. An application to Portugal. SSantos

From the 2008 SNA, a basic structure is proposed for a numerical version of a SAM. That basic structure is considered as a summary set of the flows that the SNA assumes to be observed and the controlling totals for other levels of disaggregation. From that structure, it is possible to study specific aspects and maintain the consistency of the whole system.

That basic structure can be filled in from an integrated economic accounts table, which represents the general structure of the SNA, identifying the institutional sectors in the economy as a whole, besides the rest of the world. That table (complemented with the institutional accounts, for higher levels of detail) and the "from whom to whom matrices", for specific transactions, allow for the disaggregation of the institutions accounts and for some work with the factors of production account. In turn, disaggregations at the level of the accounts of products and activities are made from the supply and use tables.

Disaggregations of the proposed structure do not affect the consistency of the whole system. Extensions, either from the national accounts or from other sources of information, pass through the convenient adjustment to, or the connection with, the whole system in order to maintain its consistency. This concern with consistency is a condition for ensuring that the network of linkages that underlies the socio-economic activity of countries is complete. Such consistency is only possible when production and institutions are worked on together. That network of linkages can only be identified and worked on in a matrix form in a tool like the SAM, which can be worked on not only for the observed but also for the non-observed activity of countries through the national accounts. The convenient coverage of that network of linkages is a necessary condition for capturing multiplier effects in subsequent modelling, which can provide important knowledge.

From the proposed SAM structure, it is also proposed that work should be performed outside the matrix format with aggregates, indicators and balancing items, which can be seen as elements extracted from our working tool in order to empirically highlight our purposes. Depending on the detail of the SAM, we can therefore calculate more or less detailed aggregates, such as Gross Domestic Product (GDP), Gross National Income, Disposable Income, etc. The same thing happens in the case of the structural indicators of the functional and institutional distribution of generated income, as well as the indicators of the use of disposable income. On the other hand, the ease with which the main items in the revenue and expenditure of the institutional sectors and of the rest of the world can be extracted from the respective rows and columns of the SAM can also be seen as a great advantage.

Particularly when the focus of the study that is being undertaken is on the role played by the households (within the institutional sectors) in the activity of a country during a pre-defined period 
Approach to the socio-economic activity of countries with a Social Accounting Matrices supported by Socio-Demographic Matrices. An application to Portugal. SSantos

(usually a year), all that can be studied through the SAM can be further complemented with a SDM. Representing the households, all the population in a country and the flows (expressed in currency units) representing its production, its consumption and its income can be worked upon within a SAM framework. In turn, when all the population in a country is worked upon within a SDM framework, its movements (expressed in numbers of human beings) can be represented in the form of a stockflow matrix, which offers many possibilities for disaggregation. Establishing the connection between the opening and the closing stock of the population for a particular period and the flows of people during that period, births, deaths, immigration, emigration and changes between groups are the movements that are recorded in a SDM. Depending on the purposes of the study, active or passive sequences can be adopted to identify those groups. Usually identifying the different age groups is the first step that should be taken prior to the definition of those sequences.

The matrices described in this paper can be either the numerical versions of the reality under study or their replication(s) after running a SAM or SDM-based model(s) in order to try out policy measures or other types of changes and to identify the corresponding macroeconomic effects. In the case of replication(s), we will have one or more scenarios representing the impacts of those policy measures, which, when compared with the reality under study, can support the processes of policy decisionmaking and policy decision-taking.

Using the example of a numerical version, the analysis of the activity of Portugal in 2009 was geared towards the study of some aspects of the socioeconomics of ageing and of the informal aspects of the activity of countries. Using an algebraic version of the SAM, the performance of a number of experiments allowed for the analysis of five scenarios that resulted from changes in that same reality. For studying the socioeconomics of ageing, our attention was focused on the section of the population aged 65 and over, namely, on those who were already retired, inactive, and recipients of pensions. In the case of that population group, our attention was also focused on the flows of income that represent their receipts and expenditures. With our working tools, for the year under study, it was possible to quantify the flows of the population of the country, by age groups and economic activity. On the other hand, for those groups, it was also possible to identify the corresponding income and expenditures and the underlying structures. From the two scenarios that were experimented with, it was possible to exemplify how the macroeconomic effects of changes in those groups and in the corresponding components of income and expenditure can be quantified.

In turn, for studying the informal aspects of the activity of Portugal in 2009, our attention was focused on household unincorporated enterprises. In the case of that population group, identified in SDM, our focus was on the so called 'informally employed', who are the owners' household unincorporated 
enterprises, also known as employers and own-account workers, whether they operate with, or without, paid employees. In turn, in the SAM, our focus was, on one hand, on the flows of income generated by the informally employed, or the informal labour and, on the other hand, on the aggregate income that was received and expended by informal households - those whose main source of income is informal labour. Using an algebraic version of the SAM, the performance of a number of experiments allowed for the analysis of three scenarios that resulted from changes in that same reality. Therefore, with these illustrative applications, the above-mentioned approaches and the underlying work undertaken in the matrix format allowed for the capture of some multiplier effects and the subsequent quantification of some macroeconomic effects resulting from changes in the flows of income and expenditure of the Portuguese recipients of pensions and household unincorporated enterprises in 2009. Those effects were summarised outside the matrix format through the quantification of changes in the GDP $\mathrm{pm}_{\text {m }}$ Gross National Income and Disposable Income.

Criticisms can be made, not only of the way in which the above experiments were performed, but also of the constraints imposed by the accounting multipliers (SAM-based model). This was, however, just a simple example of what can be done with the SAM and the SDM working tools. With this presentation and the given references, the author hopes to have been able to draw attention to the potentialities of the SAM and SDM-based approaches and to show that much more can be done beyond the presented examples.

Much work can be undertaken with SAM and SDM-based approaches in studies in many different areas.

\section{References}

Inter-Secretariat Working Group on National Accounts (United Nations, European Commission, International Monetary Fund, Organisation for Economic Cooperation and Development and World Bank) - ISWGNA, System of National Accounts 2008, Series F, No. 2, Rev. 5, United Nations, New York, 2009.

Keuning S. and Ruijter W., "Guidelines to the construction of a Social Accounting Matrix", Review of Income and Wealth, 34, 71-100, 1988.

Lequiller F., Blades D., Understanding National Accounts, Organisation for Economic Co-operation and Development (OECD), Paris, France, 2006.

Pyatt, G., "Some Early Multiplier Models of the Relationship between Income Distribution and Production Structure", Economic Systems Research, 13, 139-163, 2001. 
Approach to the socio-economic activity of countries with a Social Accounting Matrices supported by Socio-Demographic Matrices. An application to Portugal. SSantos

Pyatt, G., "Some Relationships between T-Accounts, Input-Output Tables and Social Accounting Matrices", Economic Systems Research, 11, 365-387, 1999.

Pyatt, G., "Fundamentals of Social Accounting”, Economic Systems Research, 3, 315-341, 1991.

Pyatt, G., "SAMs, the SNA and National Accounting Capabilities", Review of Income and Wealth, 37, 177-198, 1991a.

Pyatt, G., “A SAM Approach to Modeling”, Journal of Policy Modeling, 10, 327-352, 1988.

Pyatt, G., "Commodity Balances and National Accounts: a SAM Perspective", Review of Income and Wealth, 31, 155-169, 1985.

Pyatt, G. and Roe, A., Social Accounting for Development Planning with Special Reference to Sri Lanka, Cambridge University Press, Cambridge, UK, 1977.

Pyatt, G. and Round, J., "Distributional Invariance and the Design of SAMs", Economic Systems Research, 24, 251-273, 2012

Pyatt, G. and Round, J., "Accounting and Fixed Price Multipliers in a Social Accounting Matrix Framework", in G. Pyatt, and J. Round, (coord.), Social Accounting Matrices. A Basis for Planning. A World Bank Symposium, World Bank, 52-69, 1985.

Round, J., "Constructing SAMs for Development Policy Analysis: Lessons Learned and Challenges Ahead”, Economic Systems Research, 15, 161-183, 2003.

Round, J., "The Structure of the European Economy: a SAM Perspective”, in J. Round, (ed.), The European Economy in Perspective. Essays in Honour of Edward Nevin, University of Wales Press, Cardiff, 59-83, 1994.

Round, J., “A SAM for Europe: Problems and Perspectives”, Economic Systems Research, 3, 249268, 1991.

Santos S., "Socio-Economic Studies with Social Accounting and Socio-Demographic Matrices. An application to Portugal“"Working Paper No.16/2013/ DE (Departamento de Economia)/UECE (Unidade de Estudos sobre a Complexidade em Economia) - ISEG (Instituto Superior de Economia e Gestão)/UL (Universidade de Lisboa), 2013.

Santos S., "A SAM (Social Accounting Matrix) approach to the policy decision process". Working Paper No.28 /2012/ DE (Departamento de Economia) /UECE (Unidade de Estudos sobre a Complexidade em Economia) - ISEG (Instituto Superior de Economia e Gestão)/UTL (Universidade Técnica de Lisboa), 2012. 
Santos S., "A quantitative approach to the effects of social policy measures. An application to Portugal, using Social Accounting Matrices", EERI (Economics and Econometrics Research Institute) RP (Research Papers) 2010/33; MPRA (Munich Personal RePEc Archive) Paper No. 23676, 2010.

Santos S., From the System of National Accounts (SNA) to a Social Accounting Matrix (SAM)-Based Model. An Application to Portugal, Edições Almedina, Coimbra-Portugal, 2009.

Santos S., "Modelling Economic Circuit Flows in a Social Accounting Matrix Framework. An Application to Portugal”, Applied Economics, 39, 1753-1771, 2007.

Santos S., "Portuguese net borrowing and the government budget balance. A SAM approach", Journal of Policy Modeling, 26, 703-717, 2004.

Stone, R., "Nobel Memorial Lecture 1984. The Accounts of Society", Journal of Applied Econometrics, 1(1), 5-28, 1986.

Stone, R., "Demographic Input-Output: An Extension of Social Accounting”, in: I.Sohn (coord), Readings in Input-Output Analysis: Theory and Applications, Oxford University Press, USA, 151172, 1986a.

Stone, R., "The Disaggregation of the household Sector in the National Accounts", in G. Pyatt, and J. Round, (coord.), Social Accounting Matrices. A Basis for Planning. A World Bank Symposium, World Bank, 145 - 185, 1985.

Stone, R., "Working with what we have: how can existing data be used in the construction and analysis of socio-demographic matrices?", Review of Income and Wealth, 28(3), 291-303, 1982.

Stone, R., Aspects of Economic and Social Modelling, Editions Droz, Genéve (Suisse), 154p, 1981.

Stone, R., "Towards a System of Social and Demographic Statistics", Studies in Methods, Series F, Nº18, United Nations, New York, 198p, 1975.

Stone, R., “A System of Social Matrices”, Review of Income and Wealth, 19(3), 143-166, 1973.

Stone, R., “An Integrated System of Demographic, Manpower and Social Statistics and its Links with the System of National Economic Accounts", Sankhyā: The Indian Journal of Statistics, 33(1-2), 1$184,1971$.

Stone, R., "The Social Accounts from a consumer's point of view. An outline and discussion of the revised United Nations System of National Accounts", Review of Income and Wealth, 12(1), 1-33, 1966. 